\title{
TEORÍA DE PROTOTIPOS Y FUNCIONALIDAD SEMÁNTICA
}

\author{
José Luis Cifuentes HonRubia \\ (Universidad de Alicante)
}

\begin{abstract}
RESUMEN
This paper shows an expositive and critical path of prototypes' theory and its relevance to semantic analysis. From a grammar's methodological view, prototypes are understood simply as effects, that is giving account the differences between different members of a same category -not the differences in functional concept which gives account of category and its categorical being-. So, the prototype effect's idea can be valid to explain basic ideas as meaning (understood as constructive schema, being senses sanctionables totally or partly from meaning) or the relation between differents associated meanings to the same expression which is organised as familiar resemblances.
\end{abstract}

\section{CATEGORIZACIÓN, DISCRECIÓN Y PROTOTIPOS}

La identificación de lo lingüístico-inmanente como objeto de la investigación y su definición en función del «valor» de los diferentes elementos considerados constituye la aportación más importante del estructuralismo.

La definición de las distintas categorías lingüísticas en términos de sus respectivos valores descansa en el principio básico de la discreción de las unidades consideradas (Saussure 1969:191-206; Jakobson, Fant \& Halle, 1951). Toda categoría lingüística constituiría una clase cuyos límites estarían perfectamente acotados en relación con los de otras categorías diferentes, y la adscripción de un individuo a una clase habría de ser positiva o negativa, mas en modo alguno una cuestión de grado. Sin embargo, semejante principio ha de ser cuestionado con vistas a una más fiel concepción de los mecanismos lingüísticos. Tal cuestionamiento, sin embargo, en el ámbito hispánico ha sido muy pobre, y ello a pesar de que ya desde hace tiempo se cuestionase y difundiera esta perspectiva (Sánchez de Zavala, 1977 y, especialmente, Bosque, 1977). 
Desde un punto de vista exclusivamente psicológico, una primera justificación de la validez y necesidad de una consideración de las unidades lingüísticas como unidades no discretas puede ser recabada de las conclusiones del estudio de Berlin y Kay sobre los términos de color (Berlin \& Kay, 1969). Frente a la actitud habitual en las investigaciones antropológicas sobre este tipo de fenómenos (consistente en atender fundamentalmente a los aspectos diferenciales de distintas culturas), Berlin y Kay han destacado cómo, pese a la atestiguada diversidad de los nombres de color, el número de términos de colores básicos es verdaderamente limitado. Considerando como términos básicos aquellos compuestos de una sola palabra y que nombran sólo colores y no objetos (verdemanzana), ninguna lengua contendría más de 11 nombres básicos de color.

Hablantes de diferentes lenguas fueron sometidos a una prueba consistente en identificar los colores a los cuales los nombres básicos de cada una de sus lenguas se refieren, y los resultados de tal experiencia mostrarían que, produciéndose una gran variación en los límites de los términos, la elección del mejor ejemplo o representante de cada uno de ellos sería muy similar para hablantes de 20 lenguas diferentes. Berlin y Kay llamarían a los puntos en el espacio de color en que se producen las elecciones más generalizadas «puntos focales» (1969: 13).

El trabajo mencionado pondría de manifiesto otro hecho especialmente significativo: que, habitualmente, la identificación de los colores no básicos o no focales se realizaría sirviéndose, de manera aproximativa, de las categorías focales más semejantes, lo que implica concebir el espectro cromático en lugar de como conjunto de clases discretas diferentes, como un continuo en el que, junto a esos puntos focales claramente distintos, las diferentes categorías cromáticas se difuminan en sus límites, en el caso de los colores no básicos.

Las conclusiones del estudio de Berlin y Kay entrañan, según E. Rosch, importantes consecuencias tanto desde el punto de vista antropológico como psicológico. En un nivel teórico elemental podría concluirse que hay áreas de espacio cromático que son, en lo que a su perceptibilidad se refiere, más «destacadas» que otras, y que estas áreas son, a su vez, más o mejor codificables lingüísticamente, pudiendo ser recordadas mejor (Rosch, 1973; 1977; 1988).

De estos y otros trabajos (Heider, 1970) la conclusión que extraerá Rosch es que existen colores más «destacados», prominentes o distintivos en razón de propiedades que les son inherentes, y que tales colores, los que más inmediatamente atraen la atención, son más fácilmente recordados. Cuando los nombres de las distintas categorías son aprendidos, éstos serán identificados con los aspectos más prominentes de la realidad, y sólo en un segundo momento resultarán generalizados para referir otros «denotata» similares. Sucederá así que los colores focales se convertirían en prototipos para las distintas categorías de color, en una especie de imagen idealmente representativa para otras tantas variaciones cromáticas dentro de una misma categoría (Rosch, 1973: 14).

E. Rosch ha propuesto extender esta caracterización de la operatividad de los procesos de categorización a otros ámbitos diferentes como el de las formas 
geométricas o las expresiones faciales de emoción (1973: 125).

Lo fundamental de esta propuesta está en delimitar una imagen de los procesos de categorización radicalmente distinta de la habitual. Frente a la segunda, que considera una categoría como un conjunto de propiedades bien definidas que determinan la pertenencia/no pertenencia según sean o no satisfechas por un objeto, Rosch estará proponiendo considerar toda categorización como una selección de prototipos, de elementos especialmente representativos, por sus diferencias máximas respecto de los de otras categorías. Al mismo tiempo, se admite que las clases así elaboradas sirven para albergar también, aunque de manera no perfecta, sino aproximativa, a otros elementos alejados en mayor o menor grado de las características que definen el prototipo.

Y cambiar el concepto de categoría es cambiar no sólo nuestro concepto de la mente, sino también nuestra comprensión del mundo. Las categorías son categorías de cosas (Lakoff, 1987: 9-10): ya que comprendemos el mundo no sólo en términos de cosas individuales sino en términos de categorías de cosas, hay una tendencia a atribuir existencia real a estas categorías, pero no se trata de representar lo individual - categorías conceptuales subjetivas-, por ello, cambiar el concepto de categoría mismo es cambiar nuestra comprensión del mundo, afectando este cambio también a la gramática o al concepto mismo de cientificidad.

Así, Rosch se centró sobre dos implicaciones: a) si las categorías son definidas sólo por las propiedades que todos los miembros muestran, entonces ningún miembro será mejor ejemplar que otro, y b) si las categorías son definidas sólo por propiedades inherentes de los miembros, entonces las categorías serán independientes de las peculiaridades de los seres que hacen la categorización. Rosch demostró a través de sus estudios, que las categorías, en general, tienen mejores ejemplares (prototipos) y que todas las capacidades humanas específicas juegan un papel en la categorización. Podemos resumir en cuatro grandes puntos los estudios de categorización natural iniciados por Rosch (Dubois, 1991b: 34): 1) Las categorías se organizan en estructuras jerarquizadas de tipo taxonómico; las categorías se determinan por relaciones de discriminación intercategorial y de similitud o parecido intracategorial, y no de una manera independiente unas con otras según los criterios de condiciones necesarias y suficientes. 2) Existe un nivel de categorización privilegiado: el nivel de base, que se define de manera operativa como el nivel de abstracción para el que las categorías poseen el mayor número de atributos en común, que implican movimientos comunes, que presentan una similitud de formas subjetivas, y que son identificables a través del dibujo de formas medias. 3) Los objetos de las categorías naturales son descritos de mejor manera mediante correlatos de atributos y relaciones de parecido perceptivo o funcional que por listas de rasgos independientes unos con otros. 4) En un mismo nivel de organización, los ejemplares de una categoría pueden ser situados sobre un gradiente de tipicalidad; ciertos ejemplares, los prototipos, serán juzgados como muy representativos de las categorías, mientras que otros podrán ser menos representativos. 
Sin embargo, sus planteamientos no están ajenos a críticas en cuanto a sus implicaciones linguiísticas: por un lado, Coseriu (1990: 242-243) ha afirmado que el problema planteado no es propiamente el del significado, en definitiva no es un problema de linguística o semántica, sino el de la constitución de las categorías objetivas; la inclusión de objetos o hechos en determinada categoría, concluyendo que designación y significado deben separarse. Por otro lado, Rastier (1991b: 260-270; 1991c: 181 y ss.) critica la hipótesis universalista con fundamento biológico que parece desprenderse de los trabajos de Rosch: la categorización con la que opera dicha investigadora es independiente de las clasificaciones linguísticas (o, en todo caso, anterior), y el significado en cuestión no tiene nada en común con el lingüístico. Estas críticas, semejantes a las de Coseriu, las especifica más pormenorizadamente: tanto los experimentos de Berlin \& Kay como los de Rosch consideran el estudio de los colores para demostrar que su categorización es independiente de las clasificaciones lingüísticas, lo cual testimonia sus preocupaciones universalistas: el color es una categoría universal y físicamente cuantificable. Esto supone 3 conclusiones fundamentales: a) la estructura del léxico está determinada por la realidad, no por la cultura; b) las palabras son etiquetas para designar cosas; c) las lenguas son nomenclaturas.

Así pues, para Rosch y sus colegas, al confundir significado y designación, las categorías no son más que etiquetas sobre conceptos. La teoría de prototipos es parcial, y no concierne más que a uno de los niveles de categorización. Una categoría no es una clase léxica, sino una clase de conceptos; es preciso subrayar que Rosch adopta un punto de vista realista, aunque define la categoría como una clase de objetos: por categoría se entiende un cierto número de objetos considerados como equivalentes, siendo generalmente designados por nombres. El nivel de base no tiene relación necesaria con el léxico: es un nivel de abstracción conceptual. Se han hecho pruebas lingüísticas para confirmar su existencia, pero sin pretender en ningún momento definirlo (Rastier, 1991b: 266; 1991c: 185).

Para que la teoría de la categorización y, por ende de los prototipos, fuese aplicable en lingüística, sería preciso que el léxico de las lenguas estuviese organizado como una taxonomía de tipo lineano, de forma que sus categorías no concernieran más que a una sola jerarquía, consideraciones éstas evidentemente inapropiadas, salvo para determinadas clasificaciones técnicas o metalenguajes. Al proceder de una teoría taxonómica de la categorización, la teoría psicológica del prototipo es inaplicable en lingüística sin una refundición completa.

Las categorías del nivel de base no pueden estar lingüísticamente definidas porque el léxico parece reflejar la estructura de las clases reales de objetos naturales $o$ artificiales. Esto se adecúa a la concepción tradicional - aristotélica-de la significación, que depende filosóficamente del realismo empírico: las clases léxicas fundamentales o, al menos, su prototipos, están fundados en la naturaleza. Ciertamente Rosch concede que todas las categorías no tienen un fundamento perceptivo evidente y muchas podrían ser relativas a las culturas. Los prototipos naturales se limitarían a aquellos que son definidos por restricciones 
perceptivas (sobre los colores y las formas especialmente). Sea como sea, en la práctica experimental, las categorías aparecen como elementos cuyo carácter cultural no ha sido tomado en cuenta. Además, al hablar Rosch del prototipo como una ficción gramatical conveniente, está equiparando el prototipo con una cierta imagen ideal de la categoría, con lo que no pueden ser concebidos los prototipos como principios organizadores de las categorías (Rastier, 1991b: 271; 1991c: 191).

Así pues, Rastier concluye que los psicólogos y antropólogos citados minimizan la contextualidad lingüística, considerando los factores culturales como secundarios, posteriores o inesenciales. Rosch llega a admitir la incidencia de las culturas en el sistema de las categorías, e incluso en la definición de algunos atributos, pero estima que estas construcciones no invalidan el hecho estructural de un orden superior que es la coocurrencia de los atributos en el mundo real. En cuanto al contexto lingüístico, no es evocado más que para confirmar los resultados obtenidos a partir de las palabras aisladas: la tipicalidad y el nivel de base no serán estudiados ni definidos en contexto (Rastier, 1991b: 276-277; 1991c: 195-196), por lo que concluye señalando la ineficacia de importar en lexicología la noción roschiana de tipicalidad, aunque su vaga comodidad permita situarla un poco en todos los sitios. Pero a pesar de todo ello, Rastier admite explícitamente (1991b: 196) un punto de unión con la teoría de prototipos: las críticas a las condiciones necesarias y suficientes (CNS). Señala que es preciso romper con la concepción conjuntista de las clases léxicas y tratar el problema de sus diferencias internas, lo cual va a suponer un punto de unión con algunos desarrollos de la teoría de prototipos, como veremos más adelante.

En otro orden de cosas, Bideaud \& Houde (1991) también han criticado la categorización prototípica per se, concluyendo que ni la perspectiva prototípica ella sola, ni el modelo lógico piagetiano por él mismo son suficientes para dar cuenta del desarrollo de las categorizaciones. Recogen la propuesta de Osherson y Smith (1981) de que la teoría de prototipos es incompleta de naturaleza, puesto que únicamente describe un aspecto limitado de la organización conceptual. La organización taxonómica de las categorías cognitivas no es más que una de las formas de la organización de los conocimientos en la memoria humana, concepción marcada por el proyecto epistemológico de la cultura occidental de clasificaciones de los objetos naturales. La teoría de prototipos no da cuenta más que de procesos de identificación que permiten determinar la pertenencia categorial, pero falla para explicar las combinaciones conceptuales y las condiciones de verdad ligadas a la inclusión de las clases. De ahí que postulen la existencia de una organización prototípica y de una organización lógica (Dubois, 1991; 36-37; Bideaud \& Houde, 1991: 69).

En realidad, no es más que en el caso de las categorías artificiales que un prototipo puede ser claramente identificado y representado materialmente a partir de una métrica explícita, pero en el caso de las categorías naturales, los datos empíricos sólo posibilitan los ejemplos más representativos de la categoría, que permiten el punto de referencia de la tipicalidad en la categoría (Dubois, 
1991b: 50): la graduabilidad en el interior de una categoría o tipicalidad es un fenómeno sólidamente establecido pero que no responde a las cuestiones relativas de pertenencia y establecimiento de las categorías o procesos de categorización.

Verdaderamente, en Rosch podemos encontrar una cierta ambivalencia de pensamiento manifestada en la oscilación entre lo universal y lo cultural, en una ilusoria reconciliación de posiciones contradictorias (Dubois, 1991b: 32), quizás debida a la diferencia entre los primeros trabajos de Rosch y los posteriores, que reflejan, entre otros aspectos, el abandono por parte de Rosch de la idea de que los prototipos reflejan la estructura de las categorías y que constituyen representaciones de categorías - como hemos visto criticado anteriormente- (Lakoff, 1987: 43). Es por ello que la prudencia opere en muchos autores a la hora de considerar el prototipo, y que simplemente se hable de efectos prototípicos. De igual manera, hubiese sido absurdo conciliar las tesis universalistas de Rosch con los fundamentos de una lingüística cognitiva que hace del prototipo elemento básico y que apuesta epistemológicamente por el «realismo experiencial» (Lakoff, 1987) o el «paradigmatismo» (Geeraerts, 1985b) o la «semántica de la comprensión» (Fillmore, 1985), y que reposan, en definitiva, en la definición del significado como como «convencionalización de un concepto» (Langacker, 1987), con lo que quedan destacados no sólo los aspectos cognitivos y referenciales presentes en el significado, sino también, y fundamentalmente, la noción de sistema y de sociedad que lo establece, quedando asentados, pues, los principios de una semántica particular.

Todo esto nos explica la afirmación tajante de Lakoff (1987: 50) de que el nivel de categorización no es independiente ni de quien lo realiza, ni de las bases sobre las que se realiza. Aunque los mismos principios pueden determinar el nivel básico, las circunstancias bajo las que estos principios se emplean determinan el sistema de categorías que resulta.

Rosch ha señalado, para evitar en lo posible las interpetaciones anteriores (Rosch, 1978: 29), que ella siempre se refiere al mundo percibido y no a un mundo metafísico sin experimentante. La noción de propiedad no es algo objetivo en un mundo independiente de los seres; por el contrario se refiere a propiedades interaccionales (Rosch, 1978: 41-42), resultado de nuestros cuerpos y nuestros aparatos cognitivos. Tales propiedades interaccionales forman grupos en nuestra experiencia, y la estructura de prototipos y de nivel básico pueden reflejar tales agrupaciones. Ello explicará, entre otra cosas, que Lakoff (1987: 45) pretenda que los efectos prototípicos dependen de la naturaleza de modelos cognitivos.

\section{LENGUA Y MANIFESTACIONES PROTOTÍPICAS}

Es muy importante señalar que los efectos prototípicos se producen no sólo en la estructura conceptual no lingüística, sino también en las propias estructuras 
lingüísticas; y ello es debido a que las estructuras lingüísticas forman parte del aparato cognitivo general: las categorías linguiísticas son tipos de categorías cognitivas. Así, en el campo de los fenómenos lingüísticos, se han señalado aspectos de características prototípicas.

Charles J. Fillmore (1975) ha destacado la inoperatividad de la conceptuación discreta de las unidades lingüísticas en el ámbito de la semántica léxica. Formas como «viudo» o «soltero», lejos de funcionar como categaorías discretas definibles mediante un conjunto preciso de características perfectamente acotables, muestran un comportamiento aproximable al de las categorías cromáticas estudiadas por Berlin \& Kay. Así, la categoría «soltero» incluirá como miembro no-central, no prototípico a elementos como «papa», «sacerdote», «monja», que, a pesar de su marginalidad con relación a los miembros más representativos, no quedarían fuera de ella. Algo parecido sucedería respecto de la pertenencia de un individuo cuya esposa hubiera fallecido mientras los trámites de divorcio se llevaban a cabo, respecto de la categoría «viudo».

Linda Coleman \& Paul Kay (1981) han propuesto, siempre en el dominio de la semántica léxica, una definición no discreta de la categoría «mentira», que incluiría, junto a miembros centrales o prototípicos como (1), otros marginales como (2); diseñándose de esta forma una categoría con al menos dos grados de pertenencia:

\section{(1) MENTIRA}
a) (lo propuesto) $P$ es falso
b) El hablante $(S)$ cree que $P$ es falso
c) Al emitir $P, S$ pretende perjudicar a $A$

\section{(2) MENTIRA PIADOSA}
a) P es falso
b) $S$ cree que $P$ es falso

\section{3) MENTIRA}

MENTIRA

MENTIRA PIADOSA

Una de las disciplinas linguísticas más pormenorizadamente desarrollada y donde - tal vez por ello - el principio de discreción de las unidades y su fun- 
cionamiento «binario» han sido más férreamente asumidos es, sin duda, la fonología. Sin embargo, Jaeger y Ohala (1984) han mostrado la pertinencia de una perspectiva no-discreta para la categorización en inglés de los rasgos fonemáticos / tanterior/, / tsonorant/ y / \pm voice/. A través de un cuidadoso experimento, los autores citados habrían comprobado cómo las categorías en cuestión, lejos de ser procesadas discretamente y mediante oposiciones binarias, mostrarían un perfil difuso con diferentes grados de pertenencia por lo que a sus miembros se refiere.

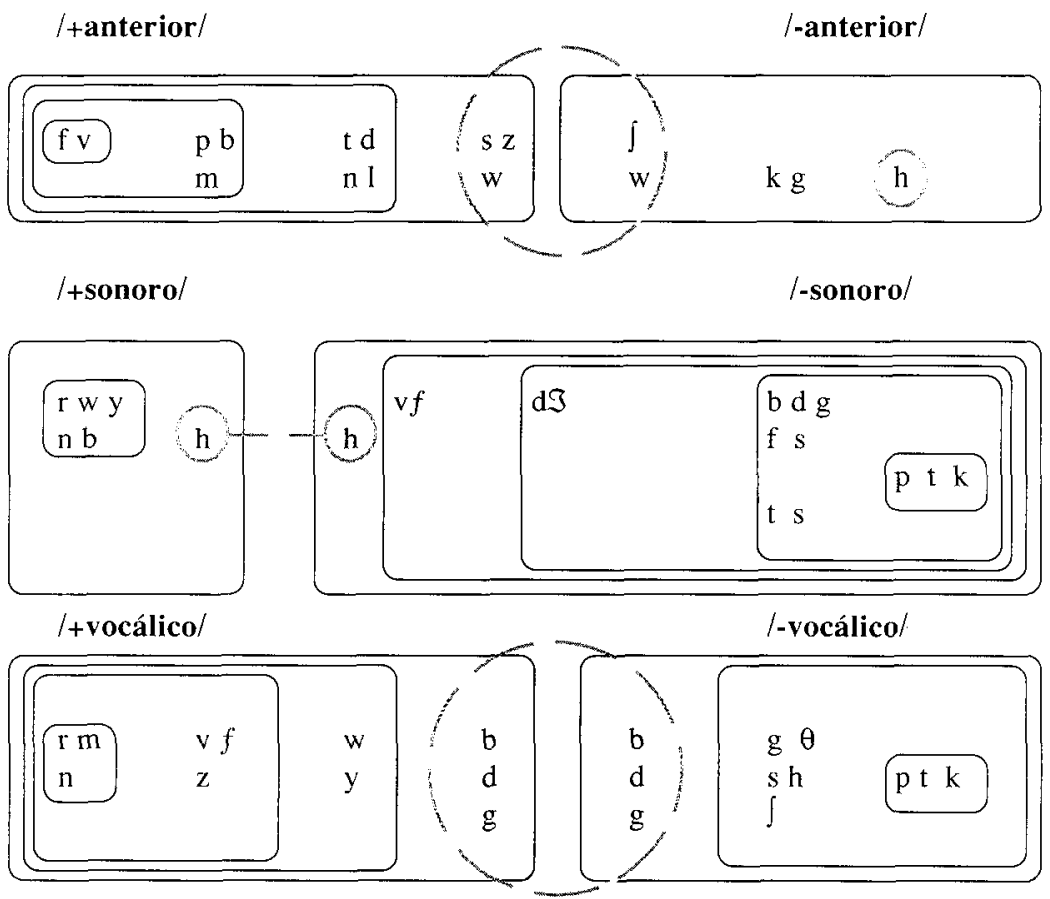

Las categorías fonémicas, en general, son comprendidas en términos de sus miembros prototípicos. Las realizaciones no prototípicas se relacionan con el prototipo por medio de reglas fonológicas (Jaeger, 1980). Los trabajos citados se dirigen a una unificación de la fonología y otros aspectos de la cognición, lo que supone una auténtica innovación que requiere una reevaluación de la teoría fonológica.

Las investigaciones a que hemos aludido tienen, en su mayoría, una orientación psicolingüística evidente (Vera, 1990: 58-65). Podrían, por ello, ser puestas en 
relación con el plano del «habla» y al margen, por tanto, de los «lícitos» intereses de la investigación lingüística, reducida por definición al estudio del ámbito de la «lengua».

La pertinencia de una perspectiva como ésta para la caracterización de mecanismos inequívocamente adscribibles al plano de la «lengua»es, sin embargo, indudable.

Además de sus ya clásicas aportaciones al estudio de los «hedges», Lakoft ha formulado diferentes caracterizaciones sintácticas utilizando la perspectiva categorial en cuestión. Según Lakoff (1977), la causatividad se representa en la gramática de la mayoría de las lenguas por una variedad de tipos, sugiriendo que las categorías de los tipos de causatividad muestra efectos prototípicos. Podemos dar cuenta de estos efectos si asumimos que la causatividad prototípica se comprende en términos de un conjunto de propiedades interaccionales:

1. Hay un agente, que hace algo.

2. Hay un paciente, que sufre un cambio a un nuevo estado (el nuevo estado es típicamente no normal o inesperado).

3. Las propiedades 1 y 2 constituyen un acontecimiento singular, entrecruzándose en el tiempo y en el espacio: el agente contacta con el paciente.

4. Parte del cambio en el paciente resulta de la acción del agente.

5. El agente es la fuente de energía y el paciente la meta; hay una transferencia de energía de agente a paciente.

6. Hay un único agente definido y un único paciente definido.

7. El agente es humano.

8. a) La acción del agente es intencionada.

b) El agente mantiene el control sobre lo que hace

c) El agente es responsable de lo que sucede.

9. El agente usa sus manos, cuerpo o algún instrumento.

10. El agente mira al paciente, el cambio en el paciente es perceptible, y el agente percibe el cambio.

Los ejemplos más representativos de la causatividad tienen estas 10 propiedades. La causación involuntaria es menos representativa que la voluntaria. La causación indirecta no es prototípica, ya que incumple la regla 3. Esto puede explicar la distinción entre «matar» $\mathrm{y}$ «hacer morir».

Bybee \& Moder (1983) en el campo de la morfología, han mostrado que verbos iregulares ingleses como string/strung forman una categoría morfológica que presenta efectos prototípicos. Arguyen que verbos que forman su pasado con $\Lambda(u)$ ortográfica, forman una categoría prototípica con las siguientes propiedades: a) comienza con /s/ seguida de una o dos consonantes; b) finaliza en nasal velar; c) tiene una aguda floja delante de vocal. Aunque los verbos de categoría no pueden ser definidos por rasgos comunes, todos ellos forman parecidos familiares con el prototipo. 
En un amplio número de estudios sobre la sintaxis del inglés, J. R. Ross $(1972 ; 1973 a ; 1973 b ; 1974 ; 1981)$ ha mostrado que cualquier categoría sintáctica tiene efectos prototípicos. Incluye categorías como nombre, verbo, adjetivo, preposición, sintagma nominal, verbal, etc. Ross también ha demostrado que construcciones sintácticas inglesas muestran efectos prototípicos, por ejemplo la pasiva, la topicalización, etc. Hopper \& Thompson (1984) también han propuesto que los miembros prototípicos de las categorías sintácticas «nombre» y «verbo» pueden ser definidos en términos de funciones semánticas y discursivas. Cuentan con ejemplos de una amplia gama de lenguas que indican que nombres y verbos tienen funciones prototípicas en los discursos.

Bates y MacWhinney (1982) propusieron a partir de datos sobre la adquisición del lenguaje que la teoría de prototipos pudiera usarse para caracterizar la relación gramatical «sujeto» de la siguiente manera:

Un sujeto prototípico es agente y tópico.

Van Oosten (1984) evidenció una gran cantidad de datos que mantienen esta hipótesis y la extendieron para incluir también que: -agente y tópico son categorías naturales que se centran alrededor de prototipos, -los miembros de la categoría sujeto no pueden ser predichos completamente de las propiedades de los agentes y tópicos.

Todos estos ejemplos se refieren a trabajos pioneros en el campo de la aplicación de los efectos prototípicos a los fenómenos lingüísticos, pero constantemente están apareciendo nuevas pruebas de ello, respondiendo a la apuesta no ya de la introspección reflexiva de la teoría, sino de la descripción aplicativa. Así, también van engrosando el paradigma de clásicos los trabajos de Lakoff (1987: 377-587) y Langacker, (1990 y 1991b), o las ediciones de Rudzka-Ostyn (1988) y Tsohatzidis (1990).

En el ámbito aplicativo hispánico la aventura prototípica resulta bastante pobre. Si bien Sánchez de Zavala (1977) ya difundió la posibilidad de una lingüística cognitiva, fue Bosque (1977) quien con mayor detenimiento se centró en informar sobre el estudio de la no discreción aplicada a oposiciones metalingüísticas: morfología y sintaxis, sintaxis y semántica; dicotomía metodológicas (gramaticalidad, aceptabilidad); morfología; flexión y derivación, significado léxico y gramatical; también recoge abundantes referencias a situaciones de gradación en clases sintácticas y léxicas.

Pero es sin duda el Prof. Vera Luján quien más valiosas investigaciones ha realizado teniendo esta línea presente. Así, además de otros trabajos previos (1984; 1986) ha aplicado la teoría de prototipos a la formación de palabras (1987) como mecanismo delimitador de las formaciones productivas: la relación entre los contenidos incorporados conceptualmente en la forma sufijada debe ser prototípica. También se ha preocupado por estudiar el «se» en las construcciones 
pronominales pasivas e impersonales, así como teniendo en cuenta las formas reflexivas: la forma «se» presentará dos modos de comportamiento distintos, pero la condición de no discreción de las unidades lingüísticas va a permitir formular una única categoría, en la que los enunciados reflexivos seleccionarán todos los rasgos categoriales, y los enunciados impersonales y pasivos reflejos sólo parte de esos rasgos (1990).

Yo mismo he señalado algunas diferencias que pueden tener los elementos incluidos en la categoría «elementos relacionantes» (Cifuentes, 1989), así como algunas teorizaciones sobre la polisemia como prototipo diacrónico (Cifuentes, 1990 y 1991).

También se ha aplicado a algunas consideraciones teóricas sobre la adquisición de una lengua extranjera (Correa Beningfeld, 1992), donde se estudian algunos ejemplos de contraste en la traducción de preposiciones, con la conclusión de que pedagógicamente no hay que apoyarse exclusivamente en un único modelo de análisis semántico. Si a ello añadimos algunas comunicaciones dispersas en algún congreso' , la aportación hispánica queda terminada, excepción hecha de algunos trabajos sobre el español realizados en EE.UU².

\section{REVOLUCIÓN Y EVOLUCIÓN EN LA CATEGORIZACIÓN PROTOTÍPICA}

Lejos de plantear problema alguno desde un punto de vista metateórico, la asunción de una perspectiva no discreta en la categorización lingüística implica, pues, considerables ventajas. De un lado, supondrá incorporar a la metateoría de la descripción lingüística un tipo de mecanismos sobradamente probados en otros ámbitos científicos, y de cuya relevancia en términos psicológicos no parece haber demasiada duda. De otro, la asunción de tales mecanismos se traducirá en una comprensión mucho más aquilatada de la economía consustancial a todo sistema lingüístico, cuya rentabilidad funcional resulta claramente potenciada al admitir, en principio, la existencia de categorías estructuradas internamente e integradas por miembros diferentes.

No obstante, la idea de la «revolución roschiana» planteada por Lakoff en múltiples ocasiones debe ser mitigada (Lakoff, 1987: 39), y no ya porque se puedan rastrear precedentes en una organización no discreta de las categorías (por ejemplo Bosque, 1977, en su aplicación lingüística), sino porque, en primer lugar, la tradición histórico-filológica preestructuralista de investigación semántica en lingüística se caracteriza por una fundamental similitud

Inchaurralde Bega, 1991; Hilferty, 1991; Mendívil Giró, 1991.

Langacker 1991 b: 182-189, donde estudia el género, fundamentalmente; Maldonado, 1988 y 1991. 
metodológica con la propuesta cognitiva contemporánea - al entenderla como una disciplina hermenéutica, cuyas preocupaciones metodológicas fundamentales son la interpretación de los textos (Geeraerts, 1991: 17-23)—, y, en segundo lugar, las concepciones kantianas y fenomenológicas de la epistemología filosófica corresponden en sus aspectos básicos con la visión del conocimiento humano implicada por la teoría prototípica de la categorización (Geeraerts, 1990: 200).

Esta falsa revolución ha sido criticada, por ejemplo por Rastier (1991c: 186188) en el sentido de que plantea una platonización ingenua de Aristóteles por parte de Rosch. Así, señala su sorpresa ante la ingratitud de oponer Rosch a Aristóteles, ya que encuentra grandes semejanzas en lo concerniente a la categorización: el nivel de base corresponderá a la especie aristotélica y el nivel superordinado al género. Pero el hecho de que la categorización aristotélica sea más genérica en su aplicabilidad que la propuesta por Rosch, que sólo afecta a las categorías naturales, lleva a Rastier a señalar que, en cuanto a la categorización, la concepción roschiana, no es más que una variante empobrecedora de la concepción aristotélica. La ingenua platonización de Aristóteles queda explicada porque el prototipo manifestaría la unidad platónica de Belleza, el Bien y la Verdad (el prototipo es el verdadero representante de una categoría, el mejor ejemplar, el más puro). En definitiva parece que nos aproximamos a la idea platónica en tanto que el prototipo es el lugar de lo real que permite representar una categoría más abstracta o un universal.

El modelo aristotélico puede ser resumido desde la visión prototípica o cognitivista, en las siguientes características (Kleiber, 1990:22-23 y ss.): a) las categorías tienen fronteras claramente delimitadas; b) la pertenencia a la categoría es un problema de verdad o falsedad; c) todos los miembros de la categoría tienen un estatuto categorial igual. Al entenderse como un conjunto de condiciones necesarias y suficientes (CNS) la necesidad es sobre cada una de las condiciones, mientras que la suficiencia concierne al conjunto de condiciones necesarias. A este respecto, cuatro son los puntos de la perspectiva clásica que deben ser señalados: 1) la pertenencia a la categoría se encuentra regulada por la verificación de las CNS; 2) el significado o intensión determina la extensión o la referencia; 3) frontera claras y estatuto equivalente de los miembros de la categoría; 4) el sentido múltiple es resuelto homonímicamente mediante la distinción de referentes. El poder explicativo del modelo de CNS se limita a una dimensión horizontal: explica la pertenencia de un miembro a una categoría en relación a las categorías de las que no forma parte, pero no justifica esta pertenencia en relación a las otras categorías de las que es igualmente miembro. En definitiva, el hecho de postular fronteras rígidas impide dar cuenta del carácter difuso de la aplicabilidad referencial al igual que no permite adaptarse a los casos marginales. El modelo de CNS tiene por vocación legítima permitir 
una definición contrastiva, que indica claramente los rasgos que separan una categoría de otra. La propuesta prototípica abre las puertas a los rasgos no contrastivos; no se trata sólo de decir lo que distingue un «perro» de un «gato», sino de describir positivamente lo que es un «perro» y lo que es un «gato» (Kleiber, 1990: 74).

Supongo que el esquema de presentación anterior también puede verse acogido bajo la calificación de «caricaturesco» que juzga Parcherie (1991: 280), en el sentido de que la teoría clásica es presentada como algo monolítico transmitido de generación en generación, pero una teoría filosófica de los conceptos no se reduce a la tesis lógica de CNS, además no hay una teoría clásica, sino múltiples versiones. Por otro lado, el papel original otorgado a la tesis lógica es dar cuenta de las propiedades lógicas de los conceptos, y no de la adquisición de los conceptos o el reconocimiento de los ejemplares. Parcherie (1991: 283) señala la anécdota de que la teoría clásica es compatible tanto con posiciones relativistas como con realistas: mientras Rosch la relega al relativismo, Lakoff al realismo. Pero el hecho de que estas dos posiciones sean compatibles con la teoría clásica indica que esta última no implica por ella misma ni la una ni la otra, y que son necesarios postulados suplementarios para pasar de la simple compatibilidad a la implicación.

La teoría aristotélica si bien afirma que todos los miembros de una misma especie tienen una esencia común que los define, no implica sin embargo que todos los miembros de una especie dada sean igual de buenos representantes de la especie. Si bien Rosch maneja el género y la especie aristotélicas, no considera otras dos de las predicaciones clásicas: lo propio, que tiene el interés de escapar a la lógica de las CNS, y el accidente, aunque puede haberse usado la teoría de prototipos para dar cuenta de ellas (Rastier, 1991c: 187). La forma puede estar más o menos perfectamente realizada en los individuos, según la resistencia que ofrezca la materia, es decir, al igual que hay útiles de mayor o menor cualidad, hay individuos que realizan más o menos perfectamente la forma de su especie (Parcherie, 1991; 287-288). El proceso lógico de agrupación de los objetos en función de sus propiedades comunes es, según Aristóteles necesario, pero insuficiente: no garantiza el valor científico o la coherencia global de los recortes posibles. Para obtener esta garantía es preciso sostener la tesis lógica con un cierto número de postulados ontológicos y gnoseológicos. El objeto de la ciencia es la esencia, y la esencia de una cosa no es otra cosa que la forma en tanto determinación necesaria y completa que da cuenta a la vez de su causalidad y de su finalidad.

Así pues, quizás haya que hacer alguna concesión a Parcherie - y a Rastieren su afirmación de que las tesis anticlasicistas suponen un conocimiento parcial y limitado en su perspectiva de la misma. Aristóteles y Rosch se sitúan en paradigmas distintos: la teoría de Rosch se inscribe en el marco de una propuesta 
psicológica de la cognición, la de Aristóteles en el de una teoría del conocimiento científico (Parcherie, 1991: 291).

Esta complementación entre Aristóteles y Rosch no nos debe parecer demasiado extraña, pues Swiggers (1988), en un nivel más general, nos ha hablado de la hermenéutica aristotélica, y de la gramática especulativa medieval como continuadora, en tanto que precedentes destacados de la lingüística cognitiva, marco de la teoría de prototipos. Esta relación, extensible a los comentarios fenomenológicos que haremos más tarde, puede entenderse como prueba empírica de la validez de una teoría linguística basada en la cognición: sus axiomas y teoremas tienen una perspectiva que se extiende más allá de la descripción del lenguaje, y el tipo de comprensión realizada sobre el lenguaje al mismo tiempo nos ayuda a desenmarañar los procesos básicos del pensamiento humano (Swiggers, 1988: 621).

Swiggers señala similaridades entre Aristóteles y la Lingüística Cognitiva en cuanto a la visión de la significación como conceptualización estructurada convencionalmente, así como con respecto a la carga semántica de las unidades de contenido en su relación con los «accidentia» de las cosas, con respecto a la definición semántica de las partes del habla, y con respecto a la información semántica como contenida dentro de esquemas gramaticales (1988: 621-622). Aristóteles, contrariamente al tratamiento de Platón de las expresiones lingüísticas en términos de valores de verdad, se aproxima al lenguaje desde un punto de vista semiótico: el lenguaje es la expresión simbólica de estados psicológicos, y estos tienen que ver con nuestra relación con el mundo exterior. Esta relación, que encuentra su expresión en los signos convencionales, no puede ser comprendida aisladamente del conjunto de principios cognitivos subyacentes que articulan la percepción humana y el conocimiento. El lenguaje humano, por ello, está situado en una encrucijada psicológica, siendo la psique el receptáculo de las imágenes sensibles, epistemológicas - todas las percepciones son categorizadas según principios cognitivos invariantes-, y lógica: la expresión de nuestros estados mentales se articula según leyes formales generales del pensamiento (Swiggers, 1988; 622-623). Ahora bien, el lenguaje como expresión simbólica de la experiencia se articula sobre la posibilidad de categorización: esta categorización es flexible en que permite al hablante adaptar su estado al flujo de la realidad, estando marcada esta flexibilidad por los accidentes, que caracterizan los términos de contenido tales como verbos y nombres (Swiggers, 1988: 623).

La ontogénesis individual de contenidos cognitivos se basa en principios filogenéticos del conocimiento preexistente — causalidad, consecución, etc.La función de estos principios es permitir a los seres humanos abstraerse de lo particular y reconocer la esencia en tanto que distinta de las formas de existencia. Esta última distinción sólo puede obtenerse mediante una visión holística de la realidad, en la que la esencia y la existencia están intrínsecamente atadas. Realmente Aristóteles no elaboró una teoría lingüística, pero tiene el mérito de 
haber vinculado el lenguaje con la cognición y de haber establecido los fundamentos de la gramática especulativa de los modistas (1988: 623-624).

La gramática especulativa medieval definía las categorías gramaticales respecto de su estructura y funcionamiento sintáctico. La orientación es básicamente cognitiva y se plasma en un esquema concreto: el de los modos de significación, basados en los modos de intelección. El resultado es una descripción unificada de las clases de palabras y esquemas oracionales, específicamente en sus aspectos formales. Es el aparato formal del lenguaje, o, mejor, la organización del sistema lingüístico convencional, lo que constituye el objetivo central de la gramática. El gran mérito de los modistas reside en el explotamiento cognitivo del equiparamiento gramatical del lenguaje, al mostrar qué tipos de categorización son implicados por las clases de palabras, qué tipos de perspectivas son significadas por los modos subalternos de significación, y qué especie de tipos formales de significado son expresados por los accidentes gramaticales (Swiggers, 1988; 642).

Evidentemente hay divergencias entre los modistas y la moderna lingüística cognitiva: la semántica prototípica está sólo implícita en la gramática modista, pero no totalmente ausente. Además la gramática modista carece de una teoría de los espacios mentales y de esquemas o procesos imaginativos, para la esquematización modista no hay otra cosa sino categorización. La linguística cognitiva va más allá, acentuando la importancia de varios esquemas de imágenes y procesos imaginativos. La divergencia debe ser vista a la luz de una diferencia importante en la estrategia heurística y teleología explicatoria entre la gramática modista y la lingüística cognitiva: mientras la última se propone estudiar la gramática como estructura simbólica, a través del análisis de esquemas y unidades discursivas, la gramática modista tiene relaciones con las estructuras gramaticales en tanto que esquemas formales que suministran significado conceptual, sin integrar su uso discursivo. Pero, a pesar de estas divergencias, permanecen similaridades básicas (Swiggers, 1988: 622).

Así pues, como suele ser normal en lingüística, se pueden encontrar precedentes de cualquier «revolucionario» planteamiento, y ello incluso en las propuestas que se pretenden modificar, aunque bien es cierto que las mayores similaridades de la propuesta cognitiva se dan con dos tradiciones, como ya señalamos. Por un lado con la tradición histórico filológica, principalmente por su orientación psicológica y metodología hermenéutica, plasmadas en una orientación experiencial y cultural, y destacando la importancia de las intenciones expresivas de los usuarios del lenguaje. Incluso su principal punto de divergencia, la perspectiva histórica, puede ser parangonada en cierta medida mediante la flexibilidad en la intersección de sincronía y diacronía (Geeraerts, 1988b), aspecto éste enfatizado ahora en Gramática Cognitiva con el redescubrimiento de la noción de «historia» en Coseriu. Por otro lado, la propuesta cognitiva es fenomenológica por su 
concepción de que el conocimiento es determinado por la interacción de la actividad cognitiva del sujeto cognoscente y los resultados del objeto conocido, lo que supone que sujeto y objeto están constitutivamente presentes en su encuentro cognitivo. Esta visión también muestra un cierto estructuralismo en la medida en que concibe el conocimiento como siendo organizado en estructuras que influyen en la construcción de nuevos conocimientos precisamente por su tendencia hacia esa permanencia estructural. El carácter prototípico de la teoría especifica la naturaleza de esas categorías estructurales (Geeraerts, 1985b: 1314). Evidentemente esta correspondencia no implica que la Gramática Cognitiva confirme los últimos desarrollos de la fenomenología, como la filosofía exitencial de Heidegger, que interpreta la apertura fenomenológica al mundo como una apertura al Sein metafísico. Igualmente, fenomenólogos post-husserlianos han acentuado normalmente los aspectos cognitivos e incluso irracionales de la Sinngebung humana del mundo, convirtiendo la fenomenología en una propuesta existencialista. Además, la Gramática Cognitiva difiere de la fenomenología en que esta última no da atención a la naturaleza estructural de la intencionalidad, mientras que la Gramática Cognitiva incorpora la integración de tres factores: mundo exterior, usuario y estructuras cognitivas. En la medida en que sobrepasa la dicotomía empirismo-racionalismo, la Gramática Cognitiva tiene un carácter claramente fenomenológico. Al mismo tiempo, sin embargo, va más allá que la fenomenología al intentar dar cuenta de los aspectos estructurales de la cognición. Por ello especifica el papel activo y constructivo del individuo en función de las estructuras cognitivas existentes. Experiencia y conceptualización son actividades estructurales interactivas. Las estructuras conceptuales dadas forman experiencia, pero nuevas experiencias pueden necesitar una extensión dinámica o reorganización de una estructura existente. La flexibilidad de los prototipos las caracteriza como estructuras que continuamente se transforman mutuamente. Su estabilidad estructural no sólo confirma que tienen un papel formativo con vistas a la experiencia sino también que pueden transformarse para acomodar nuevos datos (Geeraerts, 1985b: 225-226). Las categorías prototípicas pueden adaptarse a las circunstancias cambiantes y a nuevas necesidades expresivas, a la vez que funcionan como modelos de expectativas con vistas a la realidad (Geeraerts, 1988a: 223).

Así pues, creemos suficientemente replicada la idea de Lakoff de que la perspectiva clásica de la categorización ha dominado durante dos mil años. Pero aunque la Gramática Cognitiva comparte posicionamiento metodológico con la semántica histórico filológica y, filosóficamente, con la fenomenología husserliana - aunque sería interesante ver más bien su grado de coincidencia con MerleauPonty-, es mucho más que una mera vuelta a un preestructuralismo (Geeraerts, 1988b: 674).

Pero la teoría de prototipos ha dejado de ser un punto de controversia y precisión en la teoría linguística, para llegar a convertirse en uno de los pilares de 
la llamada lingüística cognitiva, que ya cuenta incluso con medios de expresión periódicos ${ }^{3}$. Desde sus orígenes psicolingüísticos, la teoría de prototipos se ha desarrollado principalmente en dos direcciones. Por un lado, los resultados y propuestas de Rosch han sido tomados por la psicolexicología formal (es decir, por la psicología que se ocupa del procesamiento de la información), que intenta idear modelos formales para la memoria conceptual humana y sus operaciones, relacionando, obviamente, sus límites con los de la Inteligencia Artificial ${ }^{4}$. Por otro lado, la teoría de prototipos ha tenido un extraordinario aumento en la investigación lingüística desde los primeros años de la década de los 80 , como se demuestra por el número de recientes monografías y volúmenes colectivos en los que la teoría de prototipos y sus planteamientos cognitivos juegan un papel principal, y es este último desarrollo el que vamos a tratar de fundamentar.

\section{TEORÍA DE PROTOTIPOS Y ANÁLISIS COMPONENCIAL}

Cuando la noción de prototipo entra a formar parte de la agenda semántica, ha sido usada a menudo como la llave que abre todas las puertas de la semántica, incluso en aquellos casos en que no hay grandes dificultades para construir una definición (A. Wierzbicka, 1989: 736-739; D. Geeraerts, 1989: 587-592). La noción de prototipo puede jugar un importante papel en semántica, pero ello siempre y cuando deje de ser usada como una «receta mágica» que resuelve todos los problemas instantáneamente y sin esfuerzo, y, especialmente, cuando deje de ser usada como una alternativa a las definiciones (Hagège, 1987: 65; Kleiber, 1990: 18; Wierzbicka, 1989: 736; Wierzbicka, 1990: 365). Empíricamente, las definiciones válidas explican la estructura semántica; y los prototipos son a menudo parte de la estructura semántica. En casos de este tipo, una explicación válida debe incluir el hacer referencia al prototipo, pero la referencia al prototipo no hace que la definición sea aplicable a algunos casos (los más típicos) e inaplicable para otros (los menos típicos). Una definición válida debe ser empíricamente adecuada, es decir, debe ser establecida de tal manera que cubra el espectros entero de uso de una palabra, expresión o construcción. No es suficiente con satisfacer únicamente los casos más comunes o típicos, las definiciones adecuadas deben reflejar tales hechos. Es por ello importante

3 En efecto, nos referimos no ya a los distintos libros o recopilaciones de artículos sobre linguística cognitiva aparecidos en los últimos años, ni tan siquiera a los números aparecidos en distintas revistas sobre teoría cognitiva y prototipos (vid. Versus, 44/45, 1986; Linguistics, 27, 1989; Intellectica, 6, 1988; Histoire, Épistémologie, Langages, XI-1, 1989; Langages, etc.), sino a la joven revista Cognitive Linguistics nacida en 1990, órgano de expresión de la Asociación Internacional de Lingüística Cognitiva, y cuyo Presidente es $\mathrm{G}$. Lakoff.

4 Una excelente panorámica de sus resultados puede encontrarse en E. Smith \& D. Medin: 1981; y D. Medin \& E. Smith: 1984. Un interesante ejemplo de la investigación actual podemos encontrarlo en U. Neisser, 1987. 
señalar que la estructura semántica no puede ser manifestada por medio de sesiones en un laboratorio psicolingüístico o sociolingüístico.

Ha sido, seguramente, la reacción contra el análisis componencial propuesto por Katz y Fodor (1963) lo que ha producido la negativa impresión de que la teoría de prototipos rechaza cualquier tipo de análisis componencial. Esto es una falsa concepción, por la simple razón de que no puede haber una descripción semántica sin algún tipo de análisis componencial (D.Geeraerts, 1989: 588). Coseriu, dejándose llevar por esa impresión - aunque falsa-, ha criticado la semántica de prototipos en este sentido. Así, señala que las propiedades prototípicas son análogas a los rasgos distintivos o CNS, con la diferencia de que no se reconocen como necesarios ni como suficientes para la constitución y delimitación de las categorías, lo que ha llevado en la práctica a la aplicación de las CNS al prototipo (Coseriu, 1990: 243-244). Pero no le falta razón a Coseriu al señalar que la semántica clásica a la que se opone la semántica de prototipos no es la Semántica Estructural Europea, sino una semántica logicista que no considera las palabras en sus relaciones de significación con otras palabras de una lengua determinada, sino sólo en sus relaciones de designación - coincidiendo con el análisis componencial de Katz y Fodor citado más arriba-(Coseriu, 1990: 245246). Es así que, a pesar de sus críticas, Coseriu diseña el futuro de una hipotética semántica de prototipos, que deberá basarse en una renuncia al postulado de los prototipos como generadores de categorías, lo que atribuiría a los prototipos un papel mucho más modesto, y en dejar de oponerse a la semántica analítica como teoría general de la categorización, todo ello bajo la siempre necesaria delimitación entre designación y significado (Coseriu, 1990: 281). La paradoja estriba en que ese futuro diseñado por Coseriu hace ya tiempo que es presente en algunos autores.

El hecho de que no haya características esenciales correspondientes a un término supone la necesidad de explicitación de las bases sobre las que se aplica. Wittgenstein ya nos habló a este propósito de los criterios: los criterios no son fijados ni por la experiencia, que establecen generalizaciones inductivas, ni por la necesidad lógica, que establece suposiciones, son fijados por la convención con lo que queda destacado su carácter metodológico-. Si los conceptos dependen de los criterios, entonces, contrariamente a la doctrina de Frege, no tienen límites discretos, y no son más circunscritos por sus criterios que un juego por sus reglas. Es por ello que cuando se enseña a alguien la significación de una palabra describimos ejemplos de su aplicación, de ahí que la noción de concepto puede ser representada por un esquema, y un esquema que especifica no un conjunto de condiciones necesarias y suficientes, sino las características típicas. Pero esto ha sido algo usual en psicología (Johnson-Laird, 1983: 189-190). Y usual es también reconocer que diferentes palabras pueden seguir distintos tipos de análisis, componencial y prototípico (Johnson-Laird, 1983: 216-223; Cuyckens, 1984: 72-77; Givon, 1986: 99), en paralelo con lo ya señalado anteriormente de 
la necesidad de una organización prototípica, pero también lógica, para dar cuenta del desarrollo de las categorizaciones.

Pero junto a ello, ya venimos señalando que prototipo y componencialidad no están reñidos. Para Dubois (1986: 132) el análisis de prototipos supone una hipótesis de descomposición en unidades de representación. La propuesta prototípica se concibe como alternativa a las CNS, pero no a los rasgos semánticos mismos. Kleiber (1990: 68-69) ha señalado a este respecto la semejanza de la propuesta de semas aferentes de Rastier (1987) y la teoría de prototipos. Uno de los aspectos que sí predica la teoría de prototipos es el abandono del análisis en rasgos independientes, y por ello de una verificación rasgo a rasgo. La idea a la que llegamos (Kleiber, 1990: 70) es que la descripción de los objetos de las categorías naturales gana al ser efectuada en términos de correlatos de atributos, y no por una lista de propiedades sin relaciones unas con otras ${ }^{5}$. Cuando los miembros prototípicos son descritos en términos de «clusters» de propiedades, estos reagrupamientos de propiedades forman «gestalts», es decir, son psicológicamente más simples que las partes. Así pues, las propiedades constituyentes del prototipo no pueden ser simples datos enciclopédicos, sino que deben presentar una cierta pertinencia lingüística, en respuesta a Coseriu. Y esta pertinencia linguística evidentemente se obtiene mediante un juego de relaciones paradigmáticas y sintagmáticas: el contenido de un término no viene dado de forma aislada. Las palabras están taxonómicamente organizadas en la mente, en el sentido de que constituyen jerarquías elaboradas a partir de una red de oposiciones sémicas o rasgos distintivos subyacentes a la manifestación linguíistica. El hecho de que tengan un contenido analítico exhaustivo o sólo sea posible una organización prototípica no obsta a que sus interrelaciones jueguen un papel en la determinación no ya de los límites de sus extensiones sino fundamentalmente de su uso adecuado y de la interpretación discursiva ".

Según Coseriu (1990: 252), la semántica de las CNS - la semántica estructuralista americana-considera las palabras aisladamente, en relación con las cosas o los hechos designados, coincidiendo en ésto con la semántica de prototipos por él criticada, siendo, por tanto, sus rasgos distintivos propiedades distintivas de las cosas, en su aspecto objetivo, y rasgos constitutivos de los correspondientes conceptos en su aspecto mental. Es por ello que califique tanto a la semántica de CNS como a la de prototipos de «universal», y que le impute la no distinción entre léxico estructurado y léxico no estructurado. Sin embargo, en

Ya Greimas (Greimas-Courtés, 1982: 359), señalando las diferencias de su concepción del semema respecto de la de Pottier, comentaba que el semema no puede ser considerado como una mera colección de semas, producto de una simple combinatoria: el semema se presenta como una organización sintáctica de semas.

En parecidos términos se ha expresado también Johnson-Laird (1983: 204), reconociendo no sólo lo que pueden ser las interrelaciones taxonómicas —en paralelo con las relaciones paradigmáticas estructuralistas-, sino también la pertinencia de inferencias implícitas basadas en el contexto (1983:236) - en paralclo con las relaciones sintagmáticas, combinatorias, clasemáticas, etc.-. 
Gramática Cognitiva, las significaciones no vienen dadas de forma aislada, sino en el interior de modelos cognitivos idealizados (MCI), por lo que deben considerarse estructuradas en el sentido anteriormente expuesto. El hecho de que un prototipo evoque una escena, o, mejor, un $\mathrm{MCI}$, indica que las palabras no pueden construirse de forma aislada. Además, esta Gramática Cognitiva en modo alguno se pretende teóricamente universal, sino que siempre es relativa a las convenciones sistematizadas por cada lengua. En el fondo de toda esta problemática está la dispersión de propuestas metodológicas concretas y unificadoras de la Gramática Cognitiva, y, particularmente, de la teoría de prototipos, propio, por otro lado, de todo preliminar metateórico.

Así pues, y volviendo teóricamente al punto de partida, el análisis componencial, parece que debe haber un conjunto de rasgos descriptivos, siendo su articulación prototípica otro asunto (Wierzbicka, 1990). La noción de componentes semánticos discretos es perfectamente compatible con la noción de prototipo y con la no discreción de la referencia (Wierzbicka, 1985: 19). No es que un objeto deba tener un conjunto de rasgos necesarios y suficientes para calificar como denotado a un nombre concreto, más bien, lo que hay que conseguir es el mayor conjunto de rasgos que, tomados conjuntamente aseguren que cualquier objeto que los posea sea generalmente reconocido como miembro de la categoría en cuestión (Wierzbicka, 1985: 60).

La propuesta generativista de Jackendoff (1983) también ha criticado el análisis en CNS, pero no la descomposición semántica, ya que se asume que los lexemas tienen descomposición, aunque no en CNS. Pero estima que una teoría explicativa en términos de prototipos no es defensa alternativa $(1983 ; 109)$. Sus críticas muestran el mismo problema que venimos encontrándonos a propósito de Coseriu, etc.: qué teoría de prototipos es la criticada. Todas las críticas generalmente van dirigidas hacia las primeras propuestas roschianas sobre los prototipos, pero estas propuestas han sido igualmente criticadas, y superadas, por sus propios defensores. Así, por ejemplo, la solución alternativa defendida por Jackendoff, las reglas de preferencia, guarda notables similitudes - por no decir que se trata de una variante-con la idea del prototipo en tanto que efecto y parecido familiar, que será una de las alternativas propuestas.

Jackendoff recoge el término «reglas de preferencia» de la música ya que estas reglas no establecen decisiones inflexibles acerca de la estructura, sino preferencias relativas entre un número de análisis lógicamente posibles. Su hipótesis es que imponemos sobre una superficie musical una estructura proyectada que representa el más alto grado de preferencia en su conjunto cuando todas las reglas de preferencia aplicables son tomadas en cuenta. Tal estructura se juzgará como la más preferible, o más coherente, o más destacable, o más estable (1983: 132-133). El sistema de reglas de preferencia da a los grupos un carácter de parecido familiar. Es más, los prototipos (usa en este caso el término «estereotipo») no son directamente descritos en la teoría, sino que surgen como 
efecto. Y es el propio Jackendoff quien señala las semejanzas entre este planteamiento y el tratamiento de Rosch y Mervis de los fenómenos de parecido familiar: la agrupación musical muestra la manera en que las condiciones no necesarias para la satisfacción de un concepto - las condiciones de tipicalidadforman un sistema interactivo (1983: 136). Es por ello que el conjunto de condiciones de marcos, escenarios, etc., sean entendidos como sistemas de reglas de preferencia (1983: 141).

Una teoría adecuada sobre la comprensión del lenguaje natural necesita un componente de semántica analítica o componencial: el análisis componencial mantiene su valor para la descripción y comparación de las significaciones (Fillmore, 1986: 51). Las dificultades que surgen con el tipo de análisis neoestructuralista en rasgos semánticos no se deben al uso de la descomposición como un instrumento descriptivo, sino al estatuto atribuido al análisis en rasgos. Lehrer (1990: 370) nos dice que el estatuto de los rasgos puede cambiar de necesario a probable o posible. Varios importantes puntos deben ser señalados a este respecto (Geeraerts, 1989: 588-590):

En primer lugar, la teoría de prototipos pretende que no hay un conjunto singular de atributos que definen y conforman, de manera suficiente y necesaria, el concepto en cuestión. La noción de "prototipo» cuenta entre sus antecedente básicos con el concepto de parecido familiar de Wittgenstein (Wittgenstein, 1988: cap. I). Wittgenstein señaló que una categoría como juego no se ajusta a la defínición clásica, ya que no hay propiedades comunes compartidas por todos los miembros. Rasgos como «diversión», «competición», «suerte», «habilidad», etc., son variables. Aunque no hay una definición singular de propiedades compartidas por todos los miembros, la categoría de los juegos se encuentra unida por un cierto «parecido familiar»: los miembros de un parecido familiar se parecen entre ellos de muy distinta manera, pero no hay un conjunto de condiciones necesarias y suficientes compartidas por todos los miembros de la familia. Los juegos, a este respecto, son como las familias, ya que sus miembros son similares unos con otros de una amplia variedad de maneras, y el que no haya una colección de propiedades comunes es lo que define al juego como categoría. Los rasgos de centralidad y graduabilidad son condiciones añadidas a la categorización, no a la definición.

En segundo lugar, la teoría de prototipos es contraria a aceptar la idea de que hay una estructura semántica autónoma en las lenguas naturales, que puede ser estudiada aisladamente de otras capacidades cognitivas humanas. Los fenómenos significativos de las lenguas naturales no pueden ser estudiados aisladamente del conocimiento enciclopédico que poseen culturalmente los individuos; es precisamente la presuposición de que existe una estructura puramente lingüística de oposiciones semánticas lo que capacita a determinadas corrientes estructuralistas y neoestructuralistas a establecer la existencia de una distinción entre semántica y conocimiento enciclopédico. La teoría de prototipos tiende a minimizar la 
distinción, en principio por razones metodológicas: debido a que la categorización lingüística es un fenómeno cognitivo como las otras capacidades cognitivas del hombre, es importante estudiarla en sus relaciones con estas otras capacidades. Es por ello que las críticas de Rastier (1991c: 195-196) referidas a la minimización de la contextualidad lingüística al considerar los factores culturales como secundarios, posteriores o inesenciales, se vean restringidas, si acaso, a las primeras propuestas roschianas, como ya explicamos anteriormente, o a la discutida noción de «cue validity» (Rosch \& Mervis, 1975: 575; Lakoff, 1987: 52-54; Dubois, 1986; Blutner, 1985; Kleiber, 1990: 75-76, 88-91).

Los prototipos contienen gran cantidad de detalles ligados culturalmente que, en una premonitoria visión aristotélica, tienen que ser considerados accidentales (Taylor, 1989: 42). La teoría de prototipos observa que los matices de un concepto están conectados con distintos tipos de similaridad enciclopédica, sin que haya una definición semántica singular no ambigua que cubra todos los casos. Y el hecho de que ciertas características conceptuales sean más destacadas que otras, y que esta preponderancia sea una cuestión de gradación a lo largo de un continuo, supone que la división interna de un concepto léxico en parte semántica y enciclopédica es fundamentalmente falsa (Geeraerts, 1985b: 141142) ${ }^{7}$. Así, por ejemplo, el significado prototípico de Fillmore (1977: 81) consiste en describir la escena prototípica a partir de la cual puede desgajarse un acuerdo general y que se comprende cuando ninguna información es suministra$\mathrm{da}$, siendo los otros significados considerados como derivados o subordinados al prototipo, con lo que queda subrayado el aspecto consensual de la comunidad lingüística cultural. Fillmore considera que las palabras representan las categorizaciones de la experiencia, y cada una de las categorías se basa en el conocimiento general y la experiencia. Así, no sólo las condiciones de empleo, sino también la situación discursiva, las estructuras casuales, escénicas, cognitivas, intencionales, institucionales, culturales, sociológicas, conceptuales, en definitiva, todo lo que es necesario para utilizar y comprender la lengua parece ser tratado en términos de prototipo, lo que será sintetizado por Lakoff bajo los modelos cognitivos idealizados, que dan cuenta de los fenómenos de prototipos, y que han llevado a Coseriu a decir (1990: 255-256) que la teoría escénica y de los marcos relativa a la significación es una versión de sus consideraciones textuales a propósito del entorno, en el sentido de que las palabras no significan sólo en una zona (región en la que se conoce y emplea corrientemente un signo dependiendo sus límites de la tradición linguística), sino también en un ámbito (región en la que los objetos designados se conocen como elementos del horizonte vital de los hablantes o de un dominio orgánico de la experiencia o de la cultura, siendo sus límites no lingüísticos), y en un ambiente (región establecida social o culturalmente) (Coseriu, 1973: 311-312).

Evidentemente las propiedades constituyentes del prototipo no pueden ser simples datos enciclopédicos, sino que deben presentar una cierta pertinencia lingüística (Kleiber, 1990: 70 y ss.). 
Evidentemente la necesidad de acogerse a rasgos semánticos enciclopédicos para dar cuenta del significado ha sido algo común en el estructuralismo europeo, de ahí las consideraciones a este propósito de Villard (1991: 139) concibiendo que el análisis sémico de Pottier, por ejemplo, nunca ha sido un inventario semántico de rasgos semánticos distintivos necesarios y suficientes, sino únicamente un inventario de rasgos necesarios con una finalidad determinada y que reenvían a un referente conceptualizado, avalado en el concimiento del mundo. Pero más claro todavía es Greimas a este respecto (1982:359) cuando señala que el semema no es una unidad de significación delimitada por las dimensiones del signo mínimo; en lengua, es decir, en una perspectiva inmanente, no es sino una figura sémica, de forma que sólo en el momento de su discursivización la figura se reúne con su base contextual, seleccionando así un proceso sémico que la realiza como semema, excluyendo otros procesos posibles. Esto nos explica que Trives, por ejemplo, haya incorporado en el esquema del signo lingüístico la necesidad que hay de acogerse a rasgos enciclopédicos en los procesos de monosemización, lo que ha propuesto atender bajo la denominación de episema (Ramón Trives, 1982: 178).

Otros argumentos más específicos han sido también formulados para mostrar que la distinción entre nivel enciclopédico y nivel semántico de la estructura categorial es insostenible ${ }^{8}$.

Aunque la teoría de prototipos tiene un menor grado de formalización que las propuestas axiomáticas o componenciales, sus ventajas respecto de éstas son considerables (Geeraerts, 1983 y 1989: 590-592; Kleiber, 1990: 101-117). En primer lugar, la propuesta componencial, al ser estrictamente formal, es demasiado poderosa: no contiene restricciones sobre el rango de cambios semánticos producidos por los procesos de transformación de las definiciones componenciales. con el número adecuado de pasos transformativos, y la elección de los rasgos apropiados, cualquier definición puede ser convertida en otra, lo que es contraintuitivo. A este respecto debemos señalar que la noción de similaridad y motivación restringe la distancia conceptual entre significados antiguos y nuevos: los principios explicativos de flexibilidad mediante lazos asociativos son esencialmente prototípicos (Geeraerts, 1983: 24-25). La estabilidad estructural resultante de su flexibilidad posibilita la acomodación de nuevas experiencias (Geeraerts, 1985b: 191-192).

En segundo lugar, concierne a un número de fenómenos semánticos que han sido desconsiderados por la mayoría de las propuestas estructuralistas. Los límites difusos de las categorías, la existencia de escalas de tipicalidad para los

\& Cf. J. Haiman, 1980; D. Geeraerts, 1985b; y la multitud de trabajos que sobre teoría pragmática se han elaborado, sirva de ejemplo paradigmático E. Ramón Trives, 1980. Una aplicación de la teoría de prototipos incardinada en una visión semántica «enciclopédica», pueden ser algunos trabajos realizados sobre localización espacial: B. Hawkins, 1985; A. Herskovits, 1986; C. Vandeloise, 1986; J. L. Cifuentes, 1988 y 1989 . 
miembros de una categoría, la naturaleza flexible y dinámica de las significaciones de las palabras, la importancia de los procesos metafóricos y metonímicos como bases de esa flexibilidad. En realidad no es que estos aspectos no hayan sido tratados por otras teorías semánticas o lingüísticas, pues ejemplos de ello podemos encontrar diversos ${ }^{9}$, sino que en ninguna teoría constituían conjuntamente el eje de la formulación teórica.

En tercer lugar, la teoría de prototipos intenta ser una teoría productiva no sólo porque sus investigaciones sobre la estructura de las categorías léxicas pueden ser fácilmente aplicadas en varios campos del dominio semántico, sino también porque puede extender sus consideraciones hacia otros aspectos de la lingüística ${ }^{10}$; y es gracias a estas extensiones que la teoría de prototipos ha llegado a ser uno de los pilares de la lingüística cognitiva, que intenta dar cuenta de la interacción entre lenguaje y cognición en todos los niveles de la estructura lingüística. En este sentido, el desarrollo de la teoría de prototipos en lingüística cognitiva contiene prometedoras propuestas de una teoría cognitiva unificada de la categorización lingüística.

En cuarto lugar debemos señalar su naturaleza interdisciplinar: Ia importancia de su ligazón genética con la psicolingüística sólo puede ser totalmente apreciada enfrentándola con la teoría del lenguaje chomskyana. En la metodología chomskyana la lingüística es una ciencia cognitiva, pero descarta relacionarse directamente con los resultados de otras ciencias del conocimiento. La lingüística chomskyana pretende revelar algo acerca de la mente pero prefiere una metodología autónoma en vez del diálogo abierto con la psicología que parece estar implicado.

En quinto lugar, las definiciones componenciales sincrónicas no pueden garantizar el contener los aspectos diacrónicamente relevantes del significado (Geeraerts, 1983: 21-23). Aunque este problema diacrónico puede ser remediado al incluir un componente enciclopédico junto a un componente estrictamente semántico, las estructuras sincrónicas prototípicas tienen una ventaja: incorporan toda la información que es relevante con vistas a la flexibilidad sincrónica del concepto, y puesto que esta flexibilidad puede afectar a todos los rasgos enciclopé-dicos con él conectados, las estructuras prototípicas incluyen conocimiento enciclopédico. De esta manera no necesitan invocar un componente enciclopédico extra para explicar trazos diacrónicos, y pueden evitar las distorsiones procedentes de rígidas definiciones selectivas, teniendo un mayor valor explicativo respecto del cambio semántico. Así pues, vemos destacadas la naturaleza dinámica de una posible noción sincrónica de organización conceptual prototípica. El reconocimiento de que las categorías conceptuales no están rígidamente definidas y que combinan un número de matices

"Sirvan a modo de mero ejemplo representativo E. Coseriu, 1977: 66-102; U. Weinreich, 1966; E. M. Uhlenbech, 1970.

${ }^{10}$ Cf. G. S. Nathan, 1986, en el nivel fonológico; en morfología J. Bybee \& c. L Moder, 1983, M. Post, 1986; en sintaxis J. Van Oosten, 1986, J. R. Ross, 1987; en formación de palabras A. Vera Luján, 1987; en lingüística histórica K. Aijmer, 1985, M. Winters, 1987; en lexicografía D. Geeraerts, 1985, etc. 
a través de la acción centralizadora de un núcleo conceptual, implica la posibilidad de actualizar dinámicamente el concepto de prototipo en nuevas aplicaciones periféricas. Este carácter dinámico de los prototipos epistemológicamente constata el rasgo básico de la cognición humana de interpretar nuevos hechos a través de antiguo conocimiento (Geeraerts, 1983: 28-29).

\section{TIPOS DE PROTOTIPOS}

El atractivo de la teoría de prototipos, sin embargo, no debe obscurecer el hecho de que una exacta definición de la prototipicidad no está exenta de problemas. De ahí que la crítica de Coseriu (1990: 243) señalando que la semántica de prototipos no se preocupe esencialmente del significado, sino de la inclusión de objetos o hechos en determinada categoría no esté exenta de justificación. Así, cuando Kleiber (1990: 17-18) comenta que siendo la teoría de prototipos una teoría de la categorización, y no una teoría, en principio, de semántica léxica, muchas veces lingüistas y psicólogos no están hablando de los mismos fenómenos, además de poner de relieve la existencia de concepciones muy diferentes de la semántica de prototipos, está, sin duda, acercándonos a una posible explicación a tanta confusión. Es por ello que sea imprescindible distinguir entre la organización intercategorial de pertenencia y la organización intracategorial (Dubois, 1991 a: 21), pues ello va a suponer dos concepciones muy distintas de la noción de prototipo, siendo la primera versión blanco justificable de críticas, y habiendo sido desechada en favor de la segunda incluso por sus propios difusores (de ahí las alusiones que en alguna ocasión hemos hecho a una primera y segunda Rosch). Y por otro lado está la posible pertinencia de estos postulados para la semántica léxica.

Así pues, la pregunta que pretendemos responder es cuántos tipos de prototipos se pueden discernir y la posible utilidad de alguno de ellos.

a) Mejor ejemplar concreto reconocido por los hablantes (frecuencia, densidad, valor).

b) Entidad abstracta (imagen mental -idea platónica-, combinación de atributos típicos).

c) Término genérico.

d) Ficción cómoda.

e) Parecido familiar.

f) Estereotipos.

g) Parangones.

h) Submodelos.

i) Ejemplos destacados.

j) Tipicalidad. 


\subsection{Mejor ejemplar.}

El prototipo fue en principio concebido como el mejor ejemplar comúnmente asociado a una categoría por los sujetos hablantes, además es entendido como el elemento base a partir del cual decidir la inclusión categorial del resto de miembros, es, por tanto, entidad fundadora de la estructura categorial. La cualificación prototípica se basó fundamentalmente, en la frecuencia, siendo ésta el único garante de la estabilidad interindividual necesaria para su pertinencia $^{n}$. Los lexemas considerados como los mejores ejemplares de una categoría son los más frecuentemente citados por los miembros de esa categoría. Además, los ejemplos prototípicos de una categoría son accesibles antes y procesados más rápidamente que los ejemplos periféricos (Cruse, 1990: 383). Esto también ha sido señalado por Kleiber (1991: 108) incidiendo en su aprendizaje primero por parte de los niños. También se ha tratado de definir el mejor ejemplar como la instancia más sustituible en el seno de un determinado caso de uno o varios esquemas. Pero, como subraya Nelson (1985), el grado de sustituibilidad está en función de la frecuencia de ocurrencia de los objetos, lo que conduce a definir el prototipo como la instancia más frecuentemente prescrita para el uso en los acontecimientos o escenas de donde se abstrae la categoría. A pesar de que esta definición en principio parece diferir de las formulaciones de Rosch en términos de atributos, las dos defniciones no son antónimas (Bideaud \& Houde, 1991: 6465), en la medida en que el fenómeno de la sustituibilidad no existe más que en referencia a unos atributos que comparten los objetos concernientes en el seno de los esquemas en que se insertan.

También se ha hablado de la definición del prototipo como un ejemplar medio o bien como un ejemplar definido por un número de rasgos máximos. Pero semánticamente esta conclusión nos llevaría a efectos contraproducentes, pues

"Geeraerts (1988a:207-208) plantea varias soluciones comoexplicación de los fenómenos prototípicos: a) la frecuencia; b) combinable con la anterior es la idea de «cue validity»: las instancias prototípicas de una categoría maximiza el valor en ausencia; c) la estructura fisiológica del aparato perceptivo explicación ésta que quizás nos puede conducir a un cierto universalismo en el carácter de los prototipos; d) funcionalismo psicológico: la prototipicidad es el resultado de algunos principios profundamente asentados del funcionamiento cognitivo, que tiende a hacer más económico el sistema conceptual: más información con menor esfuerzo cognitivo. Algunos de estos principios son, por ejemplo, la flexibilidad, la estabilidad estructural o la modelación de expectativas. Geeraerts concluye que a pesar de que prefiere la hipótesis psicológica funcional para el caso concreto que estudia, esto no implica que el rechazo de los tres primeros principios deba aplicarse a todos los casos (1988a: 222). Pero, entre otras conclusiones, también sugiere - a propósito de los verbos en concreto que estudia-- que la formación prototípica puede ser influenciada por otros factores que los puramente conceptuales: necesidades estilísticas, sociolingüísticas o connotativas más que puramente conceptuales pueden determinar el uso flexible de una categoría (1988a: 227).

Esta atractiva explicación, por otro lado clásica en la semántica historicista preocupada en los cambios de significado, por ejemplo, no debe hacemos olvidar que Geeraerts está aplicando la explicación a un tipo concreto de categorías y, como él muy bien dice, otros principios explicativos pueden aplicarse en otros casos. 
en el primer caso relacionaríamos el prototipo con un archisemema y en el segundo se identificaría con el semema cuya densidad sémica es la más elevada (Rastier, 1991c: 190), con lo que seguimos sin resolver el asunto. Además, podemos mezclar cosas absurdas: los prototipos como pretendidamente principios organizadores de las categorías del mundo real y los significados prototípicos como construcciones metodológicas que dan cuenta de los usos, hipotéticamente son aspectos que se desarrollan no ya en planos distintos, la organización de la realidad y la organización metalinguística - supuestamente relacionables bajo unos principios cognitivos comunes-, sino, fundamentalmente, que supone funciones diferentes: la organización intercategorial y la construcción intracategorial..

Pero está claro desde hace tiempo que el mejor ejemplar no es un ejemplar particular. El mejor ejemplar de pájaro no es «Zipi», mi periquito, sino determinadas subcategorías como «canario», «jilguero», etc. Si las instancias particulares pudiesen considerarse prototipos, la estabilidad interindividual nunca estaría asegurada (Kleiber, 1990: 50), y es preciso que haya un acuerdo entre los sujetos sobre el prototipo (Kleiber, 1991: 104). Por tanto, si los mejores ejemplares son, si acaso, subcategorías y no instancias individuales es porque una categoría agrupa no sólo instancias particulares realmente existentes, sino también ocurrencias virtuales o contrafactuales. Al considerar los prototipos entidades no particulares, subcategorías, lo que los hablantes pueden tener en mente no es la subcategoría que constituye el mejor ejemplar, sino el concepto o imagen mental de esa subcategoría. Así pues, el prototipo parece vincularse al objeto mental asociado a una palabra en relación a la cual se efectúa la categorización ${ }^{12}$. Y claro, desde el momento en que el prototipo es concebido como representación mental, su utilidad en la definición del significado puede ser pertinente (Kleiber, 1990: 60-61).

El mejor ejemplar ha sido considerado en ocasiones como la instancia típica ${ }^{13}$ de la categoría, pero típica en tanto que usual y frecuente no sirve (Kleiber, 1991; 61-63): D. Dubois (1983), entre otros, ha demostrado que no hay relación pertinente entre prototipo y frecuencia de uso de manera que permita concluirse la determinación del prototipo mediante la frecuencia léxica. Buscar otra solución obliga a una consideración de la tipicalidad en términos de propiedades típicas o mejores, lo que supone una construcción mental constitutiva de operaciones cognitivas. No se trata por tanto de un representante real de la categoría, sino de una entidad abstracta construida sobre la base de las propiedades típicas de la categoría. Del prototipo concebido como mejor ejemplar de una categoría,

12 J.R. Huford y B. Heasley (1988: cap. 9), y C. Schwarze (1985: 78) distinguen entre el objeto mejor cjemplar de una categoría y el concepto que le corresponde.

Desclés y Kanellos (1991: 244) han expuesto claramente que no hay una sola tipicalidad, sino tipicalidades (y teorías de la tipicalidad) «más o menos típicas». 
pasando por la representación mental de ese ejemplar, parece que podemos llegar a una concepción abstracta del prototipo en tanto que combinación de atributos o propiedades típicas de una categoría, que no tiene necesidad de ser verificada por un ejemplar para ser pertinente. Ya se considere el prototipo como instancia o como combinación de rasgos, dos tipos de representación son posibles: una lista de rasgos que describen el prototipo, y una imagen o esquema que representa el prototipo y del que en algunos casos se pueden detallar rasgos (Kleiber, 1990: 66).

Pero la propuesta de las propiedades típicas se encuentra con el problema de las bases a partir de las cuales escoger los rasgos pertinentes. Es extremadamente difícil analizar los rasgos de un prototipo, ya que la identificación de criterios está interrelacionada con el almacenaje del conocimiento (Aitchison, 1987: 6062). Así, nos encontramos con el problema de la diversidad de características que confeccionan el prototipo, la dificultad de disponerlas en orden de prioridad y de conocer dónde paramos. Las propiedades del prototipo son heterogéneas, y afectan tanto a los criterios de identificación como de conocimiento. La frecuencia es un solución posible (Kleiber, 1990: 75), pero Rosch y sus colegas optan por la «cue validity». La «cue validity» es el grado de predicción para una categoría de una propiedad o atributo de un objeto (Rosch y Mervis, 1975: 575). Un atributo presentará una «cue validity» elevada para una categoría si gran cantidad de miembros de la categoría lo poseen y si pocos miembros de categorías opuestas lo verifican (Dubois, 1986, Blutner, 1985). Así pues, los miembros prototípicos serán aquellos que comparten el mayor número de propiedades con el resto de miembros de la categoría y que tienen el menor número de propiedades en común con los miembros de las categorías opuestas (Kleiber, 1990: 76).

A pesar de todo, es casi unánime el reconocimiento de que todas las categorías referenciales no se prestan fácilmente a un tratamiento prototípico. El criterio de familiaridad parece pertinente para explicar la elección de las mejores instancias de las categorías superordinadas, mientras que la tipicalidad o posesión de atributos destacables de las categorías prevalece mejor para las categorías de base. En cuanto a la explicación de la categorización por emparejamiento con el prototipo no puede ser retenida más que para los términos superordinados (Kleiber, 1990: 121-137).

\subsection{Efectos prototípicos}

El problema fundamental de pertenencia a una categoría parece pues regulado por la teoría del prototipo: la extensión de una categoría se encuentra determinada por el grado de similaridad de sus elementos con el prototipo. Pero el carácter del prototipo en tanto entidad fundadora de las categorías es también cuestionado, concluyendo su inadecuación (Kleiber, 1991: 108-109). El problema de la pertenencia es sobre qué base decidir las ocurrencias que son miembros 
de una determinada categoría y las que no. El grado de similaridad con el prototipo no puede ser invocado, al menos en los términos de Givon (1986: 90). La similitud es uno de los constructos psicológicos más difíciles (Taylor, 1989: 60-61), primero porque es un concepto gradual, y segundo porque es subjetivo. Medir la similaridad la semántica clásica lo tenía fácil: el número de rasgos compartidos, pero al rechazar el modelo clásico también se rechaza ésto, computando la similaridad no sólo sobre el número de atributos compartidos, sino que también son considerados los no compartidos. Además, el grado de similitud con el prototipo no puede ser invocado, pues sólo establece que hay una propiedad idéntica con el prototipo, lo que es insuficiente, pues esta propiedad puede poseerse también por ejemplares que no se categorizan en esa categoría (Kleiber, 1990: 140). Rechazando postular la necesidad de criterios comunes a todos los miembros de una categoría, se priva del principio teórico justificador de la existencia misma de las categorías. Los prototipos no constituyen un modelo de cálculo particular para las categorías (Rosch, 1978: 40). La tesis de que la pertenencia a una categoría se efectúa sobre la base de la similaridad con el prototipo se abandona, al igual que el hecho de que las fronteras de las categorías son difusas (Kleiber, 1991: 110).

Son estas las principales razones que han contribuido al abandono de la noción clásica del prototipo, habiéndose propuesto fundamentalmente dos grandes alternativas: la noción de «esquema» y la noción de «parecido familiar». Es el abandono del juicio de los hablantes en el reconocimiento del prototipo lo que constituye el cambio decisivo y que marca la ruptura entre la versión clásica y renovada del prototipo. Sólo permanece en esta evolución, al mismo tiempo que la idea del prototipo como fenómeno superficial, la tesis de la imposibilidad de dar cuenta de las categorías por medio de CNS. La solución para explicar la agrupación de entidades diferentes en una misma categoría es por medio de «parecidos familiares», noción que puede incluir CNS (Kleiber, 1990: 149-156): la teoría del parecido familiar es un modelo que sólo prevee, pero que no exige, que los miembros de una misma categoría puedan no tener ningún rasgo en común. Así pues, el prototipo como representante de los conceptos de las categorías y como estructuración de la categoría desaparece, sólo quedan efectos prototípicos, siendo la relación que une los diferentes miembros de una misma categoría un parecido familiar y encontrándose justificada dicha categorización por los lazos de asociación entre los diferentes ejemplares y no por una relación entre los distintos ejemplares y una misma entidad, el prototipo.

La noción de prototipo como mejor ejemplar de una categoría subsiste, pero ni tiene el estatuto de entidad fundadora de la estructura categorial ni se concibe como representación mental de la categoría ${ }^{14}$. Sólo va a ser considerado como

${ }^{14}$ Lakoff hace una distinción similar entre criterios de pertenencia, ligados a un MCr (1987: 68-76) y propiedades típicas o efectos prototípicos (1987: 58-67). 
efecto, lo que lleva a sus defensores a hablar de grados de prototipicidad más que de prototipo, resultando entonces una noción muy heterogénea, como, por ejemplo, los distintos tipos de prototipos propuestos por Lakoff (1986: 33-36; 1987: cap. 5).

El problema que queda por decidir es que la noción de parecido familiar Wittgenstein la aplica a la organización referencial y falta demostrar que las categorías metalingüísticas -como, por ejemplo, el significado- puedan tener una organización y funcionamiento similar.

En cuanto a la vinculación prototipo-esquema, en principio se entendió que un prototipo semántico asocia una palabra o frase con una imagen o esquema cognitivo prelingüístico, y los hablantes poseen la capacidad para juzgar el grado en el que un objeto (o la representación interna de él) armoniza con el esquema o imagen prototípica (Coleman \& Kay, 1981: 27) ${ }^{15}$.

Esta neoplatónica visión pronto fue reformulada en algunos puntos importantes: Langacker aplica la noción de «esquema» para dar cuenta de parte de la estructura de los usos convencionales de una lengua ${ }^{16}$. Estos esquemas se entienden como representaciones abstractas que incorporan generalizaciones que pueden ser extraídas de una disposición de sentidos específicos (Casad \& Langacker, 1985: 249), es decir, deben entenderse como construcciones metodológicas y no como entidades sustanciales fundadoras de categorías: para Geeraerts (1987: 4) un prototipo es una abstracción y construcción, debiendo ser considerado por tanto metodológicamente, y no como entidad con realidad psicológica. Noción paralela a la de Dubois (1991a: 20), quien la concibe como modelo de un fenómeno cognitivo describible de forma directa mediante sistemas simbólicos formales en el nivel metalinguiístico. Tal concepción supone un estatuto de representación cómodo y válido en un cuadro teórico de un modelo o de una teoría del mundo real. Concepción metodológica, pues, y opuesta a una concepción realista, o, mejor, idealista, platónica del prototipo como idea pura, verdadera, preexistente a la cosa, que sólo es instancia, copia o ejemplo.

Para Langacker un esquema es una estructura superordinada, siendo una caracterización abstracta totalmente compatible con todos los miembros de la categoría que define, y concibiéndose los miembros con mayor especificidad y detalle que el esquema. Pero si bien el ser miembros de la categoría no es un asunto de grado, la sanción sí lo es: en la medida en que una estructura concuerda con las unidades convencionales de la gramática, se dice que éstas unidades sancionan su uso, pudiéndonos encontrar con sanción ya total o parcial. En la medida en que la sanción depende del juicio de los hablantes más que de

${ }^{15}$ Foss \& Hakes (1978: 162) entienden el esquema de Barlett —esquema mental en el que se incorporan nuevos hechos- como un precursor de la noción de «prototipo».

${ }_{16}$ Taylor (1989: 65) há señalado las semejanzas de los esquemas de Langacker con los modelos de Hudson (1984), sindo paralela la elaboración de un esquema de Langacker con la inherencia de un modelo de Hudson. 
gramaticalidad hablamos de convencionalidad (Langacker, 1987: 63-73). La distancia entre convención y uso podemos entenderla como una fuente del cambio del lenguaje y punto crucial de la estructura linguística: los usos particulares, al igual que los juicios de categorización que los sancionan, a menudo adquieren el estatuto de unidad y alguna medida de convencionalidad; en la medida en que esto ocurra, las estructuras en cuestión acaban dentro de los confines de la gramática y cuentan como parte de la convención lingüística. Resulta claro que categorización por esquemas y categorización por prototipos son aspectos de un mismo fenómeno: en el primer caso una entidad espera ser totalmente sancionada o compatible con una representación abstracta, en el último es sólo parcialmente compatible (Langacker, 1987: 369-373).

A veces se ha criticado la propuesta esquemática (Taylor, 1989: 67-68) ${ }^{17}$ señalando que para muchas categorías de las lenguas históricas no es posible abstraer un esquema que sea compatible con todos los miembros de la categoría. Si esto lo aplicamos a la delimitación del significado lingüístico podríamos llegar al absurdo del significado único. Sin embargo, a partir de la idea de Langacker (1987:369) de que los valores de un lexema no sólo son analizables como instanciaciones de un esquema abstracto singular, sino también como extensiones de un prototipo ${ }^{18}$ podemos encontrar un principio de solución. Si delimitamos los distintos significados de un lexema como esquemas, la sanción total o parcial de los distintos usos nos dará cuenta de todo el espectro significativo $\sin$ necesidad de recurrir a la idea de significado único. En la medida en que las extensiones se convencionalicen y, metodológicamente, podamos delimitar los significados de un lexema, tendremos resuelto el problema.

Pero la idea de esquema propuesta no es nada nueva, en realidad estamos ante la noción de un concepto que puede ser representado por un esquema, y que podríamos reinterpretar en sentido kantiano, entendiendo el esquema no como una imagen, sino como un modelo que subyace a nuestra capacidad para formar una imagen (Kant, 1978: 184), con lo que se acoge también la noción dinámica de sanción. Esta vinculación también ha sido vista, en cierta manera, por Johnson-Laird (1983: 189-190) y Geeraerts (1985b: 224-225), señalando éste último que las categorías kantianas también construyen activamente y forman experiencias, al igual que los esquemas y la sanción total o parcial posibilitan experiencias actuales con expectativas constructivas. La diferencia señalada

17 Obviamos las críticas de Taylor de la no graduabilidad de los miembros por ser una ventaja, no un defecto. En cuanto a que la categorización con prototipos sea anterior a la categorización mediante esquemas, preferimos evitar esta polémica y recordar la conclusión ya expuesta de Bideaud \& Houde de la necesaria coexistencia de los procesos de categorización prototípico y lógico, que parece más similar a la propuesta esquemática de Taylor.

${ }_{18}$ Evidentemente no hay manera de predecir desde el esquema las instanciaciones o extensiones que se esperan para su convencionalización, pero en modo alguno son arbitrarias, están motivadas, en el sentido de Lakoff (1987). 
respecto de las categorías kantianas residirá en el hecho de que estas últimas están genéticamente dadas, mientras que las estructuras cognitivas esquemáticas son el resultado de un proceso de desarrollo que consiste en una interacción continua entre individuo y entorno.

\subsection{Prototipo y estereotipo}

Prototipo y estereotipo y, por extensión, semántica de prototipos y semántica de estereotipos han sido entendidas como variantes notacionales de un mismo fenómeno, dos caras de una misma realidad (Kleiber, 1990: 9-10; Martin, 1991: 152), habiéndose delimitado en algunas ocasiones por el carácter intensional del estereotipo frente al supuesto carácter extensional del prototipo (Martin, 1991: 152; Hurford \& Heasley, 1983: cap. 9; Schwarze, 1985: 78). Sin embargo, en la mayoría de los casos esta distinción no es pertinente, y el término «prototipo» puede emplearse indiferentemente para designar ambos planos, aunque pueda ser útil para distinguir entre prototipo como construcción mental y prototipo como mejor ejemplar (Kleiber, 1990: 60).

La equivalencia entre prototipos y estereotipos ha sido por ello normalmente general (Jackendoff, 1983: 136). Pero uno de los problemas subyacentes ha sido con qué noción de prototipo se asemejaba - a no ser que mantengamos la propuesta del carácter intensional vs. extensional-. Así, se ha dicho que la noción de estereotipo de Putnam parece corresponder a un modelo esquemático definido en términos de «cue validity» (Johnson-Laird, 1983: 191). Lakoff ha sido más preciso a este respecto y ha dicho que un estereotipo puede ser entendido como un marco con «cue validity» (Lakoff, 1987: 116). En esta visión, entonces, los estereotipos de Putnam parecen ser construcciones más amplias que lo que se ha venido llamando representaciones prototípicas, en el sentido de que comprenden no sólo el prototipo, sino también la información basada en el marco y escenario provisto por el contexto para la representación del prototipo (Taylor, 1989: 73).

Pero con estas reflexiones parece que estamos tendiendo a aplicar las nociones de prototipo y estereotipo a la organización contextual más que pensar propiamente en su aplicación al significado, que es la propuesta básica ${ }^{19}$. En este sentido, entonces, debemos decir que el prototipo reclama el contexto; ya hemos precisado anteriormente cómo es necesaria una interrelación entre semántica y pragmática para la organización prototípica. Además, y en palabras de Lakoff, la organización prototípica siempre es relativa a un MCI determinado (Lakoff, 1987: 68), con lo que estas posibles distinciones que venimos haciendo carecen de validez. Prototipos y estereotipos manifiestan modulaciones invisibles del

19) Lakoff (1987: 169) ha señalado la cercanía de los estereotipos de Putnam con los M.C.I., aunque los primeros están más vagamente identificados, no incuyen aspectos imaginativos y no pueden dar cuenta de las estructuras complejas, al ser representaciones individuales. 
supuestamente lenguaje libre de contexto pero con pertinencia funcional; son «valores en ausencia» que especifican dominios implícitos, condiciones, estructuras, elecciones, responsabilidades, expectativas, etc. (Ruhl, 1989: 126).

Sin embargo, aunque quizás funcionalmente estereotipo y prototipo pueden ser genéricamente intercambiables, existen profundas diferencias en el planteamiento que les da origen. Putnam (1991 -edición original 1975-) rechaza que el significado sea un estado mental, admite que el significado determina la extensión, pero el estado psicológico del hablante individual no determina lo que él diga (1991: 192).

Putnam llega a la noción de estereotipo y a la consiguiente organización del significado a partir de la hipótesis de la aplicabilidad universal de la división del trabajo: el significado llega a ser el resultado de una cooperación entre los miembros de una comunidad lingüística subdividida en dos clases diferentes: los expertos y los hablantes usuales. El trabajo linguístico que se espera de los expertos y de los hablantes usuales se traduce respectivamente en los criterios y en los estereotipos. Los primeros son medios de reconocimiento de la esencia, instrumentos de descubrimiento de su estructura física; los otros son ideas convencionales relativas a los referentes, basadas en alguna característica comúnmente atribuida a ellos; los estereotipos no suponen reconocimiento. Esto implica que en una comunidad de habla dada, sólo los expertos son capaces de determinar las extensiones de algunos términos mediante criterios relevantes. Los no expertos no necesitan conocer estos criterios ya que, en analogía con la división del trabajo no lingüístico, expertos y no expertos mantienen un continuo interés en la cooperación (Eikmeyer \& Rieser, 1981: 139). Aquellos hablantes que no adquieren un conocimiento total acerca de los criterios que determinan la extensión de algunas palabras o expresiones, no obstante adquieren algún tipo de rasgos semánticos: en vez de criterios asocian ciertos estereotipos con palabras o expresiones. Los estereotipos son entonces creencias acerca de los objetos estándar en situaciones estándar. Evidentemente los estereotipos pueden ser incorrectos, puesto que pueden depender de mitos, etc., por ello el poder de determinación de la extensión de los estereotipos usualmente varía de forma considerable. Más concretamente, el estereotipo no determina la extensión, incluso no necesita ser necesariamente verdad en su sentido científico. Se deduce que las representaciones del significado deben contener un componente que determina la extensión, aunque, en general, no necesita existir como parte del significado de las palabras en un contexto normal, ni tiene que ser conocido por cualquier miembro de la comunidad, es suficiente conocer que hay alguien entre ellos que conoce la extensión (Neubauer \& Petöfi, 1981: 365). La extensión viene determinada por algún tipo de evaluación, sin embargo, las evaluaciones son conocidas sólo a los expertos, y no forman parte del estereotipo que gobierna el uso cotidiano del lenguaje. Ya que la extensión de un término es especificada 
por su intensión, y como el estereotipo no determina la intensión, se sigue que no puede ser intensión, y ya que el estereotipo es el único concepto de muchos términos que el hablante posee, se sigue que el hablante no posee intensiones, y por ello que las significaciones no están en la mente (Johnson-Laird, 1983: 191 192).

La hipótesis de Putnam de división del trabajo lingüístico puede comprenderse como una sugerencia de que es útil en la mayoría de los casos operar con dos tipos de conocimiento acerca de un objeto, el conocimiento estereotípico y el conocimiento sólo a disposición de los expertos. Esto no significa necesariamente que las propiedades que determinan la extensión sean necesariamente diferentes para expertos diferentes, pero puede significar la intervención de distintos marcadores para distintos expertos (Neubauer \& Petöfi, 1981: 366).

Problema añadido a esta visión genérica de estereotipo y significación es que Putnam ha cambiado la concepción de los estereotipos en tanto componentes psicológicos del significado opuestos al referente físico (Sassano, 1989: 206). En la descripción tradicional un estereotipo constituía una descripción normalizada de rasgos de la clase que son típicos o normales o, en cualquier caso, estereotipados. Generalmente los rasgos centrales del estereotipo eran criterios-rasgos que en situaciones normales constituían una forma de establecer si una cosa pertenece a la clase o, al menos, condiciones necesarias (o de carácter probabilístico) de pertenencia a la clase (Putnam, 1991: 147), siendo, por tanto, el estereotipo una idea convencional de cómo parece ser, de cómo es o de cómo se comporta un $\mathrm{X}$ (Putnam, 1991: 169). El hecho de que un rasgo se incluyera en el estereotipo asociado a una palabra $X$ no significa que sea una verdad analítica de todos los $\mathrm{X}$ que tengan ese rasgo, ni que lo tengan muchos $\mathrm{X}$, ni que todos los $\mathrm{X}$ normales lo posean, ni que algunos $\mathrm{X}$ lo posean. La mayoría de los estereotipos capturan rasgos poseídos por los miembros paradigmáticos de la clase en cuestión (Putnam, 1991: 170).

Esta concepción será rechazada, entendiéndolos sin entidad, no constituyendo objetos invariantes fijos (Putnam, 1987: 271). Los estereotipos, a lo sumo, posibilitan asociaciones semánticas sin por ello contribuir a la determinación del contenido. Disponemos sólo de estándar pragmáticos y relativos al contexto para decidir cuáles de nuestras creencias están conectadas al significado de los términos (Putnam, 1986: 416).

Descartada pues toda solución psicológica al problema del significado -el estereotipo era el único resquicio psicológico-, Putnam trata de responder a las críticas de que la relación de la palabra con el mundo depende de nuestra capacidad cognitiva y una palabra sólo puede ser usada en virtud de su asociación con determinado esquema mental ${ }^{20}$, con la tesis del holismo semántico, entendida como un paso adelante hacia la reevaluación del significado en la esfera

\footnotetext{
2* Cf., por ejemplo, Johnson-laird, 1983: 204.
} 
cognitiva. La tesis fundamental del holismo es que no se puede hablar de los significados como entidades autónomas y vinculadas a las expresiones independientemente unas de otras, sino que se deben tener en cuenta en primer lugar la totalidad de nuestro conocimiento semántico, el cual constituye un continuo indivisible (Sassano, 1989: 204). Pero la concepción del holismo no viene desarrollada por Putnam en su potencialidad positiva, cual informante de las inextricables conexiones en el interior de nuestro sistema semántico, sino que es entendida sobre todo como un límite negativo a la posibilidad de definición de los significados mismos (Putnam, 1986: 416). Esto significa que, para Putnam, no podemos hablar de significados estándar o convencionales (Sassano, 1989: 206) 21 .

Una concepción holística comporta la superación de la división del significado en componentes netamente distintos, externos e internos. La esfera cognitiva, por otro lado, constituye una especie de puente entre el sujeto y el mundo objetivo exterior. Los significados deben entenderse como aquello en lo que se revela el conocimiento, es decir, como instrumentos por medio de los cuales expresamos en el lenguaje nuestro conocimiento del mundo. Tal conocimiento constituye un conjunto unitario. Y la imposibilidad de aislar los significados no es más que la imposibilidad de delimitar los lugares del conocimiento mismo, donde por conocimiento entendemos no una suma de nociones particulares presentes en la mente individual, sino una fusión de la subjetividad en general (Sassano, 1989, 207) ${ }^{22}$.

Así pues, podemos observar una correspondencia marcada entre los estereotipos de Putnam, —especialmente en su primera versión-y los prototipos de Rosch: ambos contienen los contenidos semánticos más destacables de las categorías conceptuales del lenguaje natural, además de no constituir una definición intensional rígida de la extensión de la categoría. Pero esta correspondencia no debe ocultarnos que hay dos diferencias mayores entre ellos (Geeraerts, 1985a: 30-31): la concepción del prototipo depende, fundamentalmente, de la psicolingüística, mientras que el estereotipo pertenece a un punto de vista sociolinguiístico. La teoría prototípica es una hipótesis sobre la organización del conocimiento en el sistema cognitivo individual: indica cómo las aplicaciones diversas de una categoría son organizadas alrededor de un centro conceptual flexible. Por otro lado, la teoría estereotípica es una hipótesis sobre la distribución del conocimiento lingüístico en una comunidad lingüística: indica cómo el conocimiento especializado de científicos y técnicos está extendido en la sociedad. En suma, la noción de estereotipo define la eficacia y la economía organizadora del conocimiento semántico, mientras que la noción de estereotipo define su eficacia social.

2 Postura ésta del holismo en cierta forma comparable a la consideración del significado en Trujillo (1988), entendido en tanto intuición a través de la cual acceder a cualquier aspecto de la realidad; de ahí su condición de inefable.

2.2 Dejamos de lado, de momento, las críticas a la noción de significado en Putnam, noción carente de pertinenciá lingüística. 
La segunda diferencia entre los estereotipos y los prototipos reside en el hecho de que están basados en unas concepciones opuestas de lengua natural. Putnam supone que la relación referencial entre el conocimiento y el mundo exterior es rígida ${ }^{23}$, mientras que para Rosch lo esencial es justamente la posibilidad de emplear las categorías conceptuales del lenguaje de forma que entidades que no se corresponden con la definición central pudan ser integradas en la categoría como miembros marginales.

Estas dos nociones constituyen dos perspectivas diferentes sobre un mismo fenómeno lingüístico, completándose una con otra ${ }^{24}:$ los estereotipos describen las convenciones sociales, los prototipos los principios psicológicos de economía conceptual que influyen en la categorización semántica. De igual forma podemos suponer que, en circunstancias normales, habrá una coincidencia entre estereotipos y prototipos. Por contra, la rigidez de la teoría referencial de Putnam y la flexibilidad de las categorías prototípicas son menos fáciles de conciliar, favoreciéndose las nociones de Rosch, que pueden integrarse en una teoría más general del conocimiento humano (Geeraerts, 1985a: 31). De ahí que Geeraerts concluya que la teoría de Putnam es una simplificación inaceptable de la realidad sociolingüística. Además, en una perspectiva sociolingüística, el estereotipo no es otra cosa que el nudo central de una categoría prototípica cuya periferia más alejada está formada por las idiosincrasias individuales (Geeraerts, 1985a: 37-38).

\subsection{Efecto prototípico y grados de prototipicidad}

De las primeras propuestas referidas a la constitución del prototipo, hemos llegado a unas consideraciones en las que el prototipo únicamente es entendido como efecto, de ahí que se hable de grados de prototipicidad. La asimilación del grado de representatividad con el grado de pertenencia es errónea (Kleiber, 1991: 109). Rosch (1978: 40-41) establece claramente que los prototipos no constituyen un modelo de procesamiento particular para las categorías, ni una teoría de representación de las categorías, ni teoría alguna del aprendizaje gramatical, simplemente se concebirán como una ficción gramatical conveniente referida al grado de prototipicidad. Geeraerts (1989: 592-593) resume en cuatro puntos las características típicas de la prototipicidad - la misma propuesta prototípica se concibe como teniendo una estructuración prototípica (1989: 602; 1988c; Posner, 1986: 59; Taylor, 1989: 65)—: a) las categorías prototípicas no pueden ser definidas por medio de un conjunto singular de atributos necesarios y suficientes; 2) las categorías prototípicas muestran una estructura de parecido familiar,

23 La consideración holística del significado trata de romper esa rigidez.

24 Geeraerts ha llegado a decir que prototipo y estereotipo delimitan tipos ideales diferentes de diccionarios -en conexión con los intereses constitutivos del conocimento en Habermas--: diccionarios básicos el último, y extensos diccionarios lingüísticos, especialmente históricos, el primero (Geeraerts, $1987: 7-8)$. 
más concretamente su estructura semántica toma la forma de un conjunto radial de significados agrupados e interrelacionados; 3) las categorías prototípicas muestran grados en los miembros de la categoría; 4) las categorías prototípicas se hacen borrosas en los puentes.

La armonización entre la propuesta gradual y la sanción total o parcial parece evidente, por ello que la distinción entre la propuesta de Lakoff y la de Langacker señalada por Kleiber (1990: 141-142) nos parezca artificial.

Pero esta nueva perspectiva no está exenta de problemas. Rastier (1991c: 191 y ss.) ha señalado el principal problema: al admitir el concepto de grado de tipicalidad se debe considerar la estadística de atributos que define ese grado, y no se sabe cuál es el estatuto de esos atributos ni como asegurarse de que son descomponibles, es más, Rastier critica un cierto universalismo basado en la tendencia de Rosch a minimizar el contexto. En cuanto a la propuesta de la «cue validity» - también vinculada con la frecuencia- nos lleva a un ficticio prototipo. Es por ello que tanto Rastier como Coseriu (1990: 244) nos hayan dicho que en la práctica se han aplicado las CNS al prototipo, y al no haberlo hecho de forma diferencial hayan renovado los rasgos referenciales de Katz y Fodor.

Además, Rastier (1991a y 1991c: 197-204) se dedica a señalar una serie de efectos de tipicalidad que no coinciden con los comentados por Rosch: a) los subordinados genéricos: en el seno de una clase léxica mínima (taxema) se puede encontrar un semema cuya expresión sirve también para designar el archisemema, y éste último, en tanto que elemento menos denso y menos valorado puede ser definido como un prototipo; b) los parangones: en el seno de un taxema el término más denso y valorado puede designar otros miembros del taxema, incluso el taxema mismo; c) las moléculas sémicas: son estructuras estables de componentes microsemánticos que se representan mediante un grafo conceptual a la manera de Sowa (1984). Pueden lexicalizarse de diversa manera, relacionándose las manifestaciones léxicas con diversas clases.

De los tres tipos de tipicalidad examinados por Rastier estima que ninguno coincide con las teorías roschianas: a) los subordinados genéricos y los parangones son definidos en el seno de taxemas que no son categorías difusas. Las moléculas sémicas, en tanto tipos, determinan clases de ocurrencias textuales que no tienen nada en común con las categorías roschianas. b) Puesto que las moléculas sémicas son tipos, se pueden definir grados de tipicalidad, teniendo en cuenta el número, la posición y/o el estatuto de los componentes manifestados por las ocurrencias, pero estos grados no son grados de pertenencia a una categoría. c) Los subordinados genéricos y los parangones no definen grados de tipicalidad. No son los centros organizadores de las clases léxicas.

De estas críticas Rastier concluye (1991c: 204, 1991a: 67) que los fenómenos semánticos de tipicalidad son independientes del problema de la categorización en lengua. Pero esta misma conclusión ha sido asumida en Gramática Cognitiva al distinguir entre criterios de pertenencia categorial y propiedades típicas. Es 
más, incluso el carácter de «vaguedad» ha sido criticado desde la propia teoría de prototipos (Kleiber, 1990: 143-146): vaguedad y prototipicidad no son aspectos de un mismo fenómeno; una estructuración prototípica no entraña automáticamente vaguedad.

Fillmore (1982: 32-34) distingue seis tipos de prototipos —exactamente nos dice que podemos encontrar al menos seis tipos, con lo que deja abierta la posibilidad a nuevos tipos--, pero que debemos entenderlos en tanto que efectos prototípicos, constatándose con ello que los efectos prototípicos no son homogéneos (Kleiber, 1991: 120): el prototipo no sólo puede recubrir los mejores ejemplares, sino que también puede aplicarse a partir de otros criterios sin que se asocie juicio de representatividad. Igual consideración podemos aplicar a los tipos de prototipos expuestos por Geeraerts (1988c) o Lakoff (1986: 33-36; 1987: cap. 5), o los señalados por Rastier.

Así pues, la única conclusión que parece desprenderse de todo esto es que, tras la redefinición de prototipo como independiente del procesamiento categorial, se puede hablar de grados de prototipicidad en el seno de una categoría, pero con ello sólo se quiere decir que hay diferencias en el seno de una categoría, es decir, no en su definición, sino en la aplicabilidad de los elementos que manifiestan ese concepto. Y con esta visión tan restringida del prototipo coinciden incluso sus críticos (Rastier, 1991b: 196; Coseriu, 1990: 281).

\section{CONCLUSIONES}

Del complejo y heterogéneo recorrido expositivo realizado, vemos que hay unanimidad en el modesto papel que tienen los prototipos, pues simplemente se trata de reconocer que hay diferencias en el seno de una categoría, es decir, que la aplicabilidad de un concepto a determinados elementos puede resultar de manera que no todos los elementos que manifiestan ese concepto sean de la misma manera.

Si tratamos de aplicar esta idea a las categorías lingüísticas, y más concretamente semánticas, observamos que puede ser útil y provechosa. En primer lugar, toda categoría metalingüística es una construcción metodológica, y por ello tendrá su razón de ser precisamente en su poder descriptivo. Al poder aplicarse a elementos no idénticos se gana en precisión. Por ejemplo, no todos los elementos que cumplen la función elemento relacionante tienen las mismas características, hay diferencias entre ellos pero todos realizan el concepto funcional que se pretende describir. Las categorías no tienen realidad existencial, sino funcional, se trata de construcciones metodológicas.

En el ámbito semántico se ha abusado sobremanera de la identificación de significado con prototipo, y lleva razón Coseriu al señalar que en algunas ocasiones han confundido significado con variante (1990: 257). Propuesta fun- 
damental es, pues, delimitar los significados expresados por una misma expresión -restringidos al terreno de la semántica léxica, que parece haber sido el campo de exploración de dicha aplicación prototípica-. En este sentido, entonces, cada significado puede ser entendido como una categoría - bajo la máxima de que los significados no existen, son contrucciones metodológicas, los elementos realmente existentes son los sentidos--, y esta categoría puede organizarse de forma prototípica en el sentido de que cada uso del significado evidentemente es distinto uno de otro, pero sin dejar de ser un mismo significado. La forma de representación de dicha propuesta no es otra que el concepto en sentido kantiano - con las restricciones formuladas--, es decir, no se trata de una imagen, sino de un modelo que subyace a nuestra capacidad para formar una imagen, con lo que queda explicada la visión holística del significado, en su sentido positivo. Es decir, la idea de que el significado es una intuición a través de la cual accedemos a cualquier aspecto de la realidad es válida de esta manera. Pero la inefabilidad del significado es un planteamiento erróneo, pues es sólo accesible como construcción metodológica, categorial, que es, ya que los elementos «realmente existentes» son los sentidos o usos. El significado no existe si no es como construcción, y tenemos acceso a esa construcción ya sea mediante una serie de rasgos, definiciones, ejemplos más destacados, frecuencia de uso, uso típico, etc., en definitiva según el tipo de diccionario en cuestión que planifique los significados.

Cuestión muy distinta es relacionar los diferentes significados agrupados en torno a una misma expresión, que, evidentemente, están relacionados cognitivamente mediante relaciones metafóricas y metonímicas, fundamentalmente. En definitiva están motivados en el sentido de Lakoff, pero este es un aspecto muy distinto de lo que es la organización de los significados.

Así pues, la teoría de prototipos es un aspecto interesante para dar cuenta de un hecho fundamental, las diferencias entre los miembros pertenecientes a una categoría conceptual o metodológica. Su papel es muy humilde, de ahí que parezca pretencioso proponer una semántica basada en algo tan nimio. Y proponerlo como excusa para la determinación de las variantes e invariantes de contenido me parece un abuso. Ahora bien, la consideración de los efectos prototípicos como un aspecto más dentro de una teoría del lenguaje, como propone la Gramática Cognitiva, parece más válido y acertado. La pertinencia de esta gramática, entonces, residirá en sus postulados, y el plantear la diferencia entre los miembros de una categoría metalinguística es pertinente. Más comentarios nos llevarían a plantearnos las propuestas de la Linguística Cognitiva.

Con las distintas propuestas señaladas hemos tratado de aunar posturas hasta llegar a una noción de prototipo que entendemos válida no sólo para sus defensores, sino también para aquellos que la han criticado. Pero ello será siempre y cuando no se sobredimensione lo que se quiere decir con prototipo: hay diferencias entre los miembros de una categoría metodológica. 


\section{REFERENCIAS BIBLIOGRÁFICAS}

AIJMER, K. (1985): «The semantic development of will», in J. Fisiak (ed.): Historical Semantics-Historical Word-Formation, Berlin, Mouton, págs. 11-21.

AITCHISON, J. (1987): Words in the Mind, Basil Blackwell, Oxford.

BATES, E. \& MACWHINNEY, B. (1982): «Functionnalist Approaches to Grammar», in Language Acquisition: the State of the Art, Cambridge, Cambridge University Ptress, págs. 173-218.

BERLIN, B. \& KAY, P. (1969): Basic Color Terms: their Universality and Evolution, Berkeley, University of California Press.

BIDEAUD, J. \& HOUDÉ, O. (1991): «Catégorisation, logique et prototypicalité. Aspects développementaux», in D. Dubois (ed.), págs. 55-69.

BLUTNER, R. (1985): «Prototyp-Theorien und strukturellen Prinzipien der mentalen Kategorisierung», Linguistische Studien, 125, págs. 86-135.

BOSQUE, I. (1977): «Perspectivas de una lingüística no discreta», RSEL, VII-2, págs. 155177.

BYBEE, J. L. \& MODER, C. L. (1983): «Morphological Classes as Natural Categories», Language, 59, págs. 251-270.

CASAD, E. H. \& LANGACKER, R. W. (1985): «Inside and Outside in Cora Grammar», International Journal of American Linguistics, 51-3, págs. 247-281.

CIFUENTES HONRUBIA, J. L. (1988): «Acerca de sobre, encima y arriba: análisis de las condiciones de su empleo», RESLA, 4, págs. 63-90.

CIFUENTES HONRUBIA, J. L. (1989): Lengua y Espacio. Introducción al problema de la deíxis en español, Universidad de Alicante, Alicante.

CIFUENTES HONRUBIA, J. L. (1990): «La polisemia como prototipo diacrónico», Anales de Filología Hispánica, 5, págs. 99-119.

CIFUENTES HONRUBIA, J. L. (1991): «Polisemia y lexicografía», in Actas del IV Congreso Internacional de EURALEX, Biblograf-Vox, Barcelona, págs. 265-272.

COLEMAN, L. \& KAY,P. (1981): «Prototype semantics: the english word lie», Language, 57-1, págs. 26-44.

CORREA BENINGFIELD, M. (1992): «Efecto prototípico y adquisición de una L2», Actas del VIII Congreso Nacional de Lingüística Aplicada, AESLA, págs. 17-33.

COSERIU, E. (1973): Teoria del lenguaje y lingüistica general, Madrid, Gredos.

COSERIU, E. (1977): «La creación metafórica en el lenguaje», El hombre y su lenguaje, Madrid, Gredos.

COSERIU, E. (1990): «Semántica estructural y semántica cognitiva», I Jornadas de Filología. Homenaje al Prof. F. Marsá, Universidad de Barcelona, págs. 239-282.

CRAIG, C. (ed.) (1986): Noun Classes and Categorization, John Benjamins, Amsterdam/ Philadelphia.

CRUSE, D. A. (1990): «Prototype theory and lexical semantics», in S. L. Tsohatzidis (ed.), págs. 382-402.

CUYCKENS, H. (1984): «Towards a non-unified theory of word meaning», Papers from the Parasession on lexical semantics, Chicago Linguistic Society, Chicago, págs. 71 80.

DESCLÉS, J. P. \& KANELLOS, I. (1991): «La notion de typicalité: une approche formelle», in D. Dubois (ed.), págs. 225-244.

DUBOIS, D. (1983): «Analyse de 22 catégories sémantiques du français», L'Année Psychologique, 83, págs. 465-489.

DUBOIS, D. (1986): La compréhension de phrases: représentations sémantiques et processus, Thèse de Doctorat d'Etat, Paris VIII.

DUBOIS, D. (1991 a): «Introduction: les catégories sémantiques 'naturelles': prototype et typicalité», in D. Dubois (ed.), págs. 15-27. 
DUBOIS, D. (1991b): «Catégorisation et cognition:'10 ans aprés', une évaluation des concepts de Rosch», in D. Dubois (ed.), págs. 31-54.

DUBOIS, D. (ed.) (1991): Sémantique et Cognition, CNRS, Paris.

EIKMEYER, H. J. \& RIESER, H. (1981); «Meanings, Intensions, and Stereotypes. A New Approach to Linguistic Semantics», in H. J. Eikmeyer \& H. Rieser (eds.), págs. 133-150.

EIKMEYER, H. J. \& RIESER, H. (eds.) (1981): Words, Worlds, and Contexts, Walter de Gruyter, Berlin-New York.

FILLMORE, C. J. (1975): «An Alternative to Checklist Theories of Meaning», Papers from the Ist Meeting of the Berkeley Linguistic Society, 1, Berkeley, Berkeley Linguistic Society, págs. 123-131.

FLLLMORE, C. J. (1977): «Scenes and Frame Semantics», in A. Zampolli (ed.): Linguistic Structures Processing, Amsterdam, págs. 55-81.

FILLMORE, C. J. (1982): «Towards a descriptive framework for Spatial Deixis», in R. J. Jarvella \& W. Klein (eds.): Speech, Place \& Action, London, John Wiley \& Sons, págs. $31-59$.

FILLMORE, C. J. (1985): «Frames and the semantics of understanding», Quaderni di Semantica, 12, págs. 222-254.

FILLMORE, C.J. (1986): « 'U' - semantics, second round», Quaderni di Semantica, 13, págs. 49-58.

FOSS, D. J. \& HAKES, D. T. (1978): Psycholinguistics, Englewood Cliffs, London.

GEERAERTS, D. (1983): «Prototype Theory and Diachronic Semantics: A Case Study», Indogermanischen Forschungen, 88, págs. 1-32.

GEERAERTS, D. (1985a): «Les données stéréotypiques, prototypiques et encyclopediques dans le dictionnaire», Cahiers de Lexicologie, XLVI, 1985-1, págs. 27-43.

GEERAERTS, D. (1985b): Paradigm and Paradox, Leuven University Press, Leuven.

GEERAERTS, D. (1987): «Types of semantic information in dictionaries», in R. F. Ilson (ed.): A Spectrum of Lexicography, John Benjamins, Amsterdam, págs. 1-10.

GEERAERTS, D. (1988a): «Where does prototypicality come from?», in B. RudzkaOstyn (ed.), págs. 207-229.

GEERAERTS, D. (1988b): «Cognitive Grammar and the History of Lexical Grammar», in B. Rudzka-Ostyn (ed.), págs. 647-677.

GEERAERTS, D. (1988c): «Prototypicality as a Prototypical notion», Communication \& Cognition, 21, págs. 343-355.

GEERAERTS, D. (1989): «Introduction: Prospects and problems of prototype theory», Linguistics, 27, págs, 587-612.

GEERAERTS, D. (1990): «The lexicographical treatment of prototypical polysemy», in S. L. Tsohatzidis (ed.), págs. 195-210.

GEERAERTS, D. (1991): «Grammaire cognitive et sémantique lexicale», Communications, 53, págs. $17-50$.

GIVÓN, T. (1986): «Prototypes: between Plato and Wittgenstein», in C. Craig (ed.), págs. 77-102.

GREIMAS, A. J. \& COURTÉS, J. (1982): Semiótica, Madrid, Gredos.

HAGËGE, C. (1987): «C. Craig (ed.): Noun Classes and Categorization», Bulletin de la Societé de Linguistique de Paris, LXXXII-2, págs. 64-70.

HAIMAN, J. (1980): «Dictionaries and encyclopedias», Lingua, 50, págs. 329-357.

HAWKINS, B. (1985): The Semantics of English Spatial Prepositions, University of California, San Diego.

HEIDER, E. (1970): The Dugum Dani: A Papuan culture in the highlands of West New Guinea, Chicago, Illinois.

HERSKOVITS, A. (1986): Language and Spatial Cognition, Cambridge, Cambridge University Press.

HILFERTY, J. (1991): «'Trajectors' y 'landmarks': una introducción a dos conceptos 
básicos de la Gramática Cognitiva», Actas del VI Congreso de Lenguajes Naturales y Lenguajes Formales, Barcelona, PPU, págs. 651-666.

HOLLAND, D. \& QUINN, N. (eds.) (1987): Cultural Models in Language and Thought, Cambridge, Cambridge University Press.

HOPPER, P. J. \& THOMPSON, S. A. (1984): «The Discourse Basis for Lexical Categories in Universal Grammar», Language, 60-4, págs. 703-752.

HUDSON, R. (1984): Word Grammar, Basil Blackwell.

HÜLLEN, W. \& SCHULZE, R. (eds.) (1988): Understanding the Lexicon, Meaning, Sense and World Knowledge in Lexical Semantics, Tübingen, Niemeyer.

HURFORD, J. R. \& HEASLEY, B. (1988): Curso de Semántica, Madrid, Visor.

INCHAURRALDE BEGA, C. (1991): «Aislando una semántica conceptual (prototipos y situaciones) en la descripción de las lenguas naturales», Actas del VI Congreso de Lenguajes Naturales y Lenguajes Formales, Barcelona, PPU, págs. 139-156.

JACKENDOFF, R. (1983): Semantics and Cognition, The MIT Press, Cambridge, Massachussets.

JAEGER, J. (1980): Categorization in Phonology: An Experimental Approach, Ph. D. Diss., University of California, Berkeley.

JAEGER, J. \& OHALA, J. (1984): «On the Structure of Phonetic Categories», Proceedings of the Annual Meeting of the Berkeley Linguistic Society, 10, Berkeley Linguistics Society, Berkeley, págs. 15-26.

JAKOBSON, R. - FANT, G. \& HALLE, M. (1951): Preliminaries to Speech Analysis: The Distinctive Features and their Correlatives, Cambridge, MIT Press.

JOHNSON-LAIRD, P. N. (1983): Mental Models, Cambridge University Press, Cambridge.

KANT, I. (1978): Critica de la razón pura, Alfaguara, Madrid.

KATZ, J. \& FODOR, J. (1963): «The structure of a semantic theory», Language, 39, págs. $170-210$.

KLEIBER, G. (1988): «Prototype, stéreotype: un air de famille», DRLAV, 38, págs. 1-61.

KLEIBER, G. (1990): La Sémantique du Prototype, Paris, PUF.

KLEIBER, G. (1991): «Prototype et prototypes: encore un affaire de famille», in D. Dubois (ed.), págs. 103-129.

LABOV, W. (1973): «The Boundaries of Words and their Meanings», in C. J. Bailey \& R. Shuy (eds): New Ways of Analyzing Variation in English», Washington, Georgetown University press, págs. 340-373.

LAKOFF, G. (1972): «Hedges: a Study in Meaning Criteria and the Logic of Fuzzy Concepts», Papers from the 8th Regional Meeting of the Chicago Linguistic Society, Chicago, Chicago Linguistics Society, págs. 183-228.

LAKOFF, G. (1977): «Linguistics Gestalts», Papers from the Thirteenth Regional Meeting, Chicago Linguistic Society, Chicago, págs. 236-287.

LAKOFF, G. (1986): «Classifiers as a reflection of mind», in C. Craig (ed.), págs. 13-51.

LAKOFF, G. (1987): Women, fire and dangerous things, University of Chicago Press, Chicago.

LANGACKER, R. W. (1987): Foundations of Cognitive Grammar I, Stanford University Press, Stanford.

LANGACKER, R. W. (1990): Concept, Image and Symbol, Mouton-De Gruyter, Berlin.

LANGACKER, R. W. (1991a): «A Note on the spanish personal $a$ », mecanografiado, 12 págs.

LANGACKER, R. W. (1991b): Foundations of Cognitive Grammar II, Stanford University Press, Stanford.

LEHMANN, W. P. (ed.) (1988): Prototypes in Language and Cognition, Ann Arbor, Michigan, Karoma.

LEHRER, A. (1990): «Prototype theory and its implications for lexical analysis», in S. L. Tsohatzidis (ed.), págs. 368-371.

MARTIN, R. (1991): «Typicité et sens des mots», in D. Dubois (ed.), págs. 151-159. 
MALDONADO, R. (1988): «Energetic Reflexives in Spanish», Proceedings of the Berkeley Linguistics Society, 14, págs. 153-165.

MALDONADO, R. (1991): Middle voice: The Case of Spanish 'se', Ph. D. Diss., San Diego, University of California.

MEDIN, D. \& SMITH, E. (1984): «Concepts and concept formation», Annual Review of Psychology, 35, págs, 113-138.

MENDIVIL GIRÓ, J. L. (1991): «Consideraciones sobre el carácter no-discreto de las expresiones idiomáticas», Actas del VI Congreso de Lenguajes Naturales y Lenguajes Formales, Barcelona, PPU, págs. 711-735.

NATHAN, G. S. (1986): «Phonemes as mental categories», Proceedings of the 12th Annual Meeting of the Berkeley Linguistic Society», Berkeley Linguistic Society, Berkeley, págs. $2121-224$.

NEISSER, U. (ed.) (1987): Concepts and Conceptual Development, Ecological and Intellectual Factors in Categorization, Cambridge, Cambridge University Press.

NELSON, K. (1985): «Le développement de la représentation sémantique chez l'enfant», Psychologie Française, 30, págs. 261-268.

NEUBAUER, F. \& PETÖFI, J. S. (1981): «Word Semantics, Lexicon Systems and Text Interpretation», in H. J. Eikmeyer \& H. Rieser (Eds.), págs. 343-377.

OSHERSON, D. N. \& SMITH, E. E. (1981): «On the Adequacy of Prototype Theory as a Theory of Concepts», Cognition, 9-1, págs. 35-58.

PARCHERIE, E. (1991): "Aristote et Rosch: un aire de famille?», in D. Dubois (ed.), págs. 279-294.

POSNER, M. I. (1986): «Empirical Studies of Prototypes», in C. Craig (ed.), págs. 53-61.

POST, M. (1986): «A prototype approach to denominal adjectives», in D. Kastovsky \& A. Szwedek (eds.): Linguistics Across Historical and Geographical Boundaries, $I$, Berlin, Mouton-De Gruyter, págs. 1001-1013.

PUTNAM, H. (1986): «Meaning Holism», in E. Hahn \& P. A. Schlilpp (eds.): The Philosophy of W. V. Quine», La Salle, Open Court, págs. 405-426.

PUTNAM, H. (1987): «Meaning Holism and Epistemic Holism», in U. Pothast (ed.): Theorie des Subjectivität, Frankfurt am Main, Suhrkamp.

PUTNAM, H. (1991): «El significado de 'significado'», in L. M. Valdés Villanueva (ed.): La búsqueda del significado, Tecnos-Univ. Murcia, Madrid, págs. 131-194.

RAMÓN TRIVES, E. (1980): «Nuestro hablar: proceso pragmáticamente no exento», Monteagudo, 68, págs. 13-20.

RAMÓN TRIVES, E. (1982): Estudios sintáctico-semánticos del español, l. La dinámica interoracional, Murcia, Godoy.

RASTIER, F. (1987): Sémantique Interpretative, Paris, PUF.

RASTIER, F. (1991a): «Peut-on définir sémantiquement le prototype?», Sémiotiques, I1, págs. 59-68.

RASTIER, F. (1991b): «Catégorization, typicalité et lexicologie. Préliminaires critiques», in D. Dubois (ed.), págs. 259-277.

RASTIER, F. (1991c): Sémantique et recherches cognitives, Paris, PUF.

ROSCH, E. (1973): «On the internal structure of perceptual and semantic categories», in T. E. Moore (ed.): Cognitive Development and the Acquisition of Language, New YorkLondon, Academic Press, págs. 111-144.

ROSCH, E. (1977): «Human Categorization», in N. Warren (ed.): Studies in Cross-Cultural Psychology, London, Academic Press, págs. 1-72.

ROSCH, E. (1978): «Principles of Categorization», in E. Rosch \& B. Lloyd (eds.): Cognition and Categorization, Hilldale, Laurence Erlbaum Ass., págs. 27-48.

ROSCH, E. (1988): «Coherences and categorization: a historical view», in F. S. Kessel (ed.): The Development of Language and Language Researchers, Hisllsdale, n. J., Erlbaum, págs. 373-392. 
ROSCH, E. \& MERVIS, C. (1975); «Family Resemblances: Studies in the Internal Structure of Categories», Cognitive Psychology, 7, págs. 573-605.

ROSS, J. R. (1972): «The Category Squish: Endstation Hauptwort», Papers from the Eight Regional Meeting, Chicago Linguistic Society, Chicago, págs. 316-328.

ROSS, J. R. (1973a): «A Fake NP Squish», in C. J. Bailey \& R. Shuy (eds.): New Ways of Analyzing Variation in English», Washington, Georgetown University Press, págs. 96-140.

ROSS, J. R. (1973b): «Nouniness», in O. Fujimura (ed.): Three Dimensions of Linguistic Theory, Tokyo, TEC Corporation, págs. 137-258.

ROSS, J. R. (1974): «There, there (there, (there, (there...)))», Papers form the Tenth Regional Meeting, Chicago Linguistic Society, Chicago, págs. 569-587.

ROSS, J. R. (1987): «Islands and syntactic prototypes», Papers from the $23 \mathrm{rd}$ Annual Meeting of the Chicago Linguistic Society, Chicago, Chicago Linguistic Society, págs. 309-320.

RUDZKA-OSTYN, B. (ed.) (1988): Topics in Cognitive Linguistics, John Benjaminis, Amsterdam.

RUHL, C. (1989): On Monosemy, State University of New York, Albany.

SÁNCHEZ DE ZAVALA, V. (1977): «Problemas y perspectivas metodológicas de una linguística postgenerativa», RSEL, VII-1, págs. 171-191.

SASSANO, A. (1989): «Significato e conoscenza in H. Putnam», Lingua e Stile, XXIV2, págs. 199-220.

SAUSSURE, F. (1969): Curso de Linguistica General, Losada, Buenos Aires.

SCHWARZE, C. (1985): Lexique et compréhension textuelle, Sonderforschungsbereich 99, Universität Konstanz, n⿳ 112.

SMITH, E. E. \& MEDIN, D. (1981): Categories and Concepts, Cambridge, Harvard University Press.

SOWA, J. F. (1984): Conceptual Structures, Reading (Mass.), Addison-Wesley.

SWIGGERS, P. (1988): «Grammatical Categories and Human Conceptualization: Aristotle and the Modistae», in B. Rudzka-Ostyn (ed.), págs. 621-646.

TAYLOR, J. R. (1989): Linguistic Categorization, Oxford University Press, Oxford.

TRUJILLO, R. (1988): Introducción a la semántica española, Madrid, Arco-Libros.

TSOHATZIDIS, S. L. (ed.) (1990): Meanings and Prototypes, Routledge, London \& New York.

UHLENBECH, E. M. (1979): «The dynamic nature of word meaning», Actes du 2 e Congrès International de Linguistes, II, Bucarest, L'Academie, págs. 679-685.

VAN OOSTEN, J. (1986): The Nature of Subjects, Topics, and Agents: A Cognitive Explanation, Bloomington: Indiana University Linguistics Club.

VANDELOISE, C. (1986): L'espace en français, Paris, Seuil.

VERA LUJÁN, A. (1984): «En torno a la causalidad. (Aproximación a los fenómenos recursivo-causales a la luz de una teoría de base prototípica)», Anales Univ. de Murcia, XLII, 1-2, págs. 31-50.

VERA LUJÁN, A. (1986): «Aspectos prototípicos en la categorización lingüística», Studi Orientali e Linguistici, CLEB III, págs. 355-365.

VERA LUJÁN, A. (1987): Aspectos sintáctico-semánticos en la sufijación, Universidad de Murcia, Murcia.

VERA LUJÁN, A. (1990): Las construcciones pronominales pasivas e impersonales en español, Universidad de Murcia, Murcia.

VILLARD, M. (1991): «Notion de prototype et événement», in D. Dubois (ed.), págs. 131-149.

WEINREICH, U. (1966): «Explorations in semantic theory», Current Trends in Linguistics, 3 , págs. 395-479.

WIERZBICKA, A. (1985): Lexicography and conceptual Analysis, Ann Arbor, karoma. 
WIERZBICKA, A. (1989): «Prototypes in semantics and pragmatics: explicating attitudinal meanings in terms of prototypes», Linguistics, 27, págs. 731-769.

WIERZBICKA, A. (1990): "'Prototypes save': on the uses and abuses of the notion of 'prototype' in linguistics and related fields», in S. L. Tsohatzidis (ed.), págs. 347-367.

WINTERS, M. (1987): «Syntactic and semantic space: the development of the French subjunctive», in A. G. Ramat - O. Carruba \& G. Bernini (eds.): Papers from the Seventh International Conference on Historical Linguistics, Amsterdam, John Benjamins, págs. 607-618.

WITTGENSTEIN, L. (1988): Investigaciones filosóficas, Crítica, Barcelona. 